\title{
The proteoglycan biglycan regulates expression of the B cell chemoattractant CXCL13 and aggravates murine lupus nephritis
}

\author{
Kristin Moreth, ${ }^{1}$ Rebekka Brodbeck, ${ }^{1}$ Andrea Babelova, ${ }^{1}$ Norbert Gretz, ${ }^{2}$ \\ Tilmann Spieker, ${ }^{3}$ Jinyang Zeng-Brouwers, ${ }^{1}$ Josef Pfeilschifter, ${ }^{1}$ \\ Marian F. Young, ${ }^{4}$ Roland M. Schaefer, ${ }^{5}$ and Liliana Schaefer ${ }^{1}$
}

\begin{abstract}
1Pharmazentrum Frankfurt, Institut für Allgemeine Pharmakologie und Toxikologie/ZAFES, Klinikum der JW Goethe-Universität Frankfurt am Main, Frankfurt am Main, Germany. ${ }^{2}$ Medical Research Center, University of Heidelberg, Mannheim, Germany. ${ }^{3}$ Institute of Pathology, University of Münster, Münster, Germany. ${ }^{4}$ Craniofacial and Skeletal Diseases Branch, National Institute of Dental and Craniofacial Research, NIH, Bethesda, Maryland, USA. ${ }^{5}$ Department of Internal Medicine D, University of Münster, Münster, Germany.
\end{abstract}

\begin{abstract}
CXCL13 is a key B cell chemoattractant and marker of disease activity in patients with SLE; however, the mechanism of its induction has not been identified yet. Here, we have shown that the proteoglycan biglycan triggers CXCL13 expression via TLR2/4 in macrophages and dendritic cells. In vivo, levels of biglycan were markedly elevated in the plasma and kidneys of human SLE patients and lupus-prone (MRL/lpr) mice. Overexpression of soluble biglycan in MRL/lpr mice raised plasma and renal levels of CXCL13 and caused accumulation of $B$ cells with an enhanced B1/B cell ratio in the kidney, worsening of organ damage, and albuminuria. Importantly, biglycan also triggered CXCL13 expression and B cell infiltration in the healthy kidney. Conversely, biglycan deficiency improved systemic and renal outcome in lupus-prone mice, with lower levels of autoantibodies, less enlargement of the spleen and lymph nodes, and reduction in renal damage and albuminuria. This correlated with a marked decline in circulating and renal CXCL13 and a reduction in the number of $B$ cells in the kidney. Collectively, our results describe what we believe to be a novel mechanism for the regulation of CXCL13 by biglycan, a host-derived ligand for TLR2/4. Blocking biglycan-TLR2/4 interactions might be a promising strategy for the management of SLE and other B cell-mediated inflammatory disease entities.
\end{abstract}

\section{Introduction}

There is growing evidence that extracellular matrix components, commonly thought to function purely as structural components, also act as signaling molecules and directly regulate inflammatory processes (1). Biglycan, a small leucine-rich proteoglycan (SLRP) of the ECM, consists of a protein core and up to 2 chondroitin/dermatan sulfate chains (1). Besides being sequestered in the ECM, biglycan also exists as a soluble molecule, e.g., when it is released from the ECM by proteolytic digestion or secreted by activated macrophages (2). Soluble biglycan is capable of interacting with cell surface receptors, thereby causing downstream signaling events (1). Similar to pathogen-associated molecular patterns (PAMPs), biglycan serves as an endogenous ligand for the innate immunity receptors TLR 2 and TLR4 found on macrophages (2). Binding to these receptors leads to activation and downstream signaling via $\mathrm{p} 38, \mathrm{p} 42 / 44$, and NF- $\mathrm{\kappa B}$ in a myeloid differentiation factor 88-dependent (MyD88-dependent) manner with subsequent generation of TNF- $\alpha$ and macrophage inflammatory protein-2 (MIP-2) (2). By clustering TLR2/4 and purinergic $\mathrm{P} 2 \mathrm{X} 7 / \mathrm{P} 2 \mathrm{X} 4$ receptors on macrophages, biglycan forms a multireceptor signaling complex that activates the NLRP3 (NLR family, pyrin domain containing 3) inflammasome in a ROS- and heat-shock protein 90-dependent manner, thereby driving the ASC (apoptosis-associated speck-like protein con-

Conflict of interest: The authors have declared that no conflict of interest exists. Citation for this article: J Clin Invest. 2010;120(12):4251-4272. doi:10.1172/JCI42213. taining caspase activation and recruitment domain)/caspase-1mediated maturation and secretion of IL-1 $\beta$ (3). The influence of biglycan on leukocyte species other than macrophages has not been investigated yet.

In light of the great importance of biglycan as an endogenous danger signal to be involved in the pathogenesis of kidney diseases, the scarcity of data addressing this issue is surprising. In the kidney, both intrinsic glomerular/tubulointerstitial cells and infiltrating macrophages $(4,5)$ secrete biglycan into the ECM. In the model of unilateral ureteral obstruction, biglycan has been shown to be overexpressed in tubular epithelial cells prior to infiltration of mononuclear cells, suggesting that biglycan is an early initiator of renal inflammation (5). A number of other experimental models report a striking correlation between biglycan overexpression with TLR2/4 upregulation and renal injury, thereby suggesting its potential critical involvement in TLR2/4 activation $(3,6,7)$.

SLE is a prototypical autoimmune disease, with effects on multiple organs, leading to a wide variety of symptoms and clinical features. Prevalence estimates vary widely and range as high as 1,500,000 Americans (Lupus Foundation of America), whereas a recent study by the National Arthritis Data Workgroup estimated a US prevalence of 161,000 adults with definite SLE and 322,000 with definite or probable SLE (8). Unfortunately, there is no cure for SLE. Current treatment regimens remain inadequate and are marked by incomplete disease control; progression to end-stage organ involvement continues, and current therapies carry potential risks of debilitating side effects. 

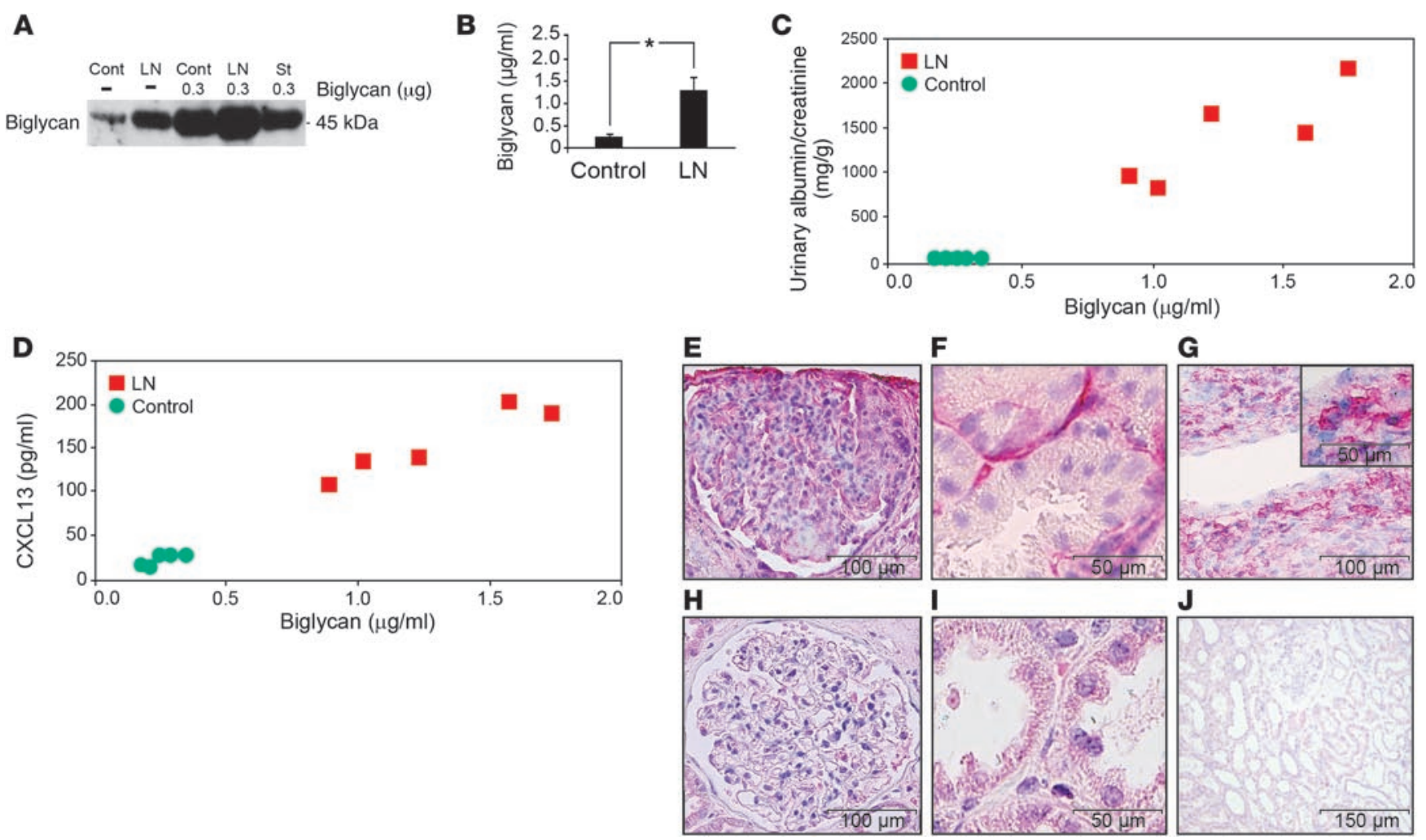

\section{Figure 1}

Overexpression of biglycan in the plasma and kidneys of patients suffering from LN. (A) Immunoblots for biglycan protein core after semipurification of $0.2 \mathrm{ml}$ plasma from healthy controls (Cont) and patients with class IV LN followed by chondroitinase ABC digestion. To standardize the assay, $0.3 \mu \mathrm{g}$ of intact biglycan (containing protein core and glycosaminoglycan chains) was added to plasma samples from a healthy control (Cont. 0.3) and a LN patient (LN 0.3) prior to semipurification. All samples were purified simultaneously and under the same conditions. Standard (St) contained $0.3 \mu \mathrm{g}$ of biglycan that was digested with chondroitinase ABC only. (B) Semiquantification of plasma biglycan calculated with consideration of assay recovery. The net biglycan gain was calculated by subtracting the control's band intensity from that of Cont 0.3 , or $\mathrm{LN}$ from LN 0.3 , and expressed as a percentage of optical density as denominated by standard. Data are given as mean \pm SD. ${ }^{*} P<0.05$. (C and D) Correlations between levels of plasma biglycan and albuminuria (C) or plasma CXCL13 (D) in individuals with $L N$ versus healthy controls. (E-J) Immunostaining for biglycan (APAAP, red color) in renal sections from LN patients (E-G) and healthy controls (H and I). Insert (G) shows a magnified view of an area with infiltrating mononuclear cells positive for biglycan. Counterstaining was done with Meyer's hematoxylin. The negative control $(\mathbf{J})$ was performed in renal sections from LN patients by using an antigen-preadsorbed (human biglycan) antiserum. Scale bars indicate the respective magnifications.

Lupus nephritis (LN), a renal manifestation of SLE, is a consequence of systemic autoimmunity based on the development of autoantibodies against nuclear antigens as well as local inflammatory tissue response to immune injury (9). The number of infiltrating macrophages and B and T lymphocytes in the kidney, regulated by inflammatory cytokines and chemokines, correlates with the degree of tissue damage and predicts the progression of renal failure in $\operatorname{LN}(10,11)$. Growing evidence indicates that B lymphocytes, beyond their role in antibody formation, play an important role in causing local renal damage in $\mathrm{LN}$. Thus, the $\mathrm{B} 1$ subset of $\mathrm{B}$ lymphocytes is responsible for the initial, $T$ cell-independent, production of antibodies required for antigen clearance and therefore appears to bridge the innate and adaptive immunity response (12-15). The chemokine CXCL13, produced mainly by monocytes/macrophages and dendritic cells, interacts with chemokine receptor CXCR5 and has recently been identified as a marker of SLE activity and an indicator of renal involvement $(10,16,17)$. Despite its biological importance as a major chemoattractant of B and B1 cells (10, $16)$, the mechanisms regulating the expression of CXCL13 have not yet been elucidated.

Several studies have underlined the role of various TLRs in the pathogenesis of LN by modulating both the innate and the adaptive immune system $(18,19)$. Activation of TLRs in LN occurs either by microbial ligands during pathogen-mediated infection or by host-derived nucleic acids. Self-nucleic acid ligands trigger a systemic response and autoantibody production via TLR3/7/9 (18, $20)$. To our knowledge, there is no data indicating the involvement of endogenous TLR ligands other than host-derived nucleic acids in the development of LN.

Here we show that the ECM proteoglycan biglycan, markedly elevated in the plasma and kidneys from patients with SLE and from lupus-prone (MRL/lpr) mice, through its interaction with TLR2/4, critically determines the systemic and renal outcome of lupus erythematosus by modulating both innate and adaptive immunity. Using a genetic approach to either eliminate or tran- 


\begin{tabular}{|c|c|c|}
\hline Characteristics & Healthy controls $(n=5)$ & $\operatorname{LN}(n=12)$ \\
\hline Age (yr) & $27 \pm 10$ & $28 \pm 10$ \\
\hline $\operatorname{Sex}(\mathrm{F} / \mathrm{M})$ & $5 / 0$ & $11 / 1$ \\
\hline Duration of SLE (mo) & - & $15 \pm 8.9$ \\
\hline SLEDAI (score) & - & $11 \pm 1.5$ \\
\hline Serum creatinine $(\mathrm{mg} / \mathrm{dl})$ & $0.78 \pm 0.13$ & $1.1 \pm 0.29$ \\
\hline Albuminuria (mg/g crea) & $<30$ & $1426 \pm 618$ \\
\hline Serum C3 (mg/dl) & $126 \pm 14$ & $57 \pm 25$ \\
\hline Serum dsDNA Ab (IU/ml) & $<5$ & $1939 \pm 24$ \\
\hline CXCL13 (pg/ml) & $21.8 \pm 5.3$ & $\begin{array}{c}154 \pm 32^{A} \\
(n=5)\end{array}$ \\
\hline
\end{tabular}

Values are given as mean $\pm \mathrm{SD}$. ${ }^{\mathrm{A} P}<0.05$ for healthy controls versus nephritic patients. crea, creatinine.

siently overexpress soluble biglycan in MRL/lpr mice, we were able to shed new light on the mechanisms of how host-derived TLR ligands promote the progression of SLE. These data clearly indicate that biglycan is a critical regulator of pro-IL- $1 \beta$ and NLRP3 expression as well as of the inflammasome/caspase-1dependent maturation of IL-1 $\beta$ in LN. The most striking result was that biglycan both in vitro and in vivo triggered the expression of CXCL13 in macrophages and dendritic cells and promoted infiltration of B and B1 cells into the kidneys of MRL/lpr mice. Biglycan-mediated induction of CXCL13 was TLR2- and TLR4-dependent and involved ROS but not the inflammasome. Biglycan overexpression aggravated renal tissue damage and albuminuria and led to a loss of organ function in MRL/lpr mice. In contrast, beneficial effects of biglycan deficiency in MRL/lpr mice suggest that blocking biglycan-TLR2/4 interactions might prove to be a promising strategy for the management of SLE, either alone or in combination with other interventions.

\section{Results}

Biglycan is enbanced in plasma and renal sections from $L N$ patients. Soluble biglycan has been shown to act as an endogenous proinflammatory trigger $(2,3)$. To address its potential involvement in the pathogenesis of LN, plasma levels of circulating biglycan were examined in samples from patients with newly diagnosed and untreated LN type IV. Proteoglycans extracted from $0.2 \mathrm{ml}$ of plasma from healthy controls and LN were semipurified, treated with chondroitinase $\mathrm{ABC}$ to remove glycosaminoglycan chains, and analyzed for biglycan protein cores by Western blotting (Figure 1A). For standardization of the assay, graded quantities of intact biglycan (protein core plus glycosaminoglycan chains) were added to plasma samples from healthy controls and LN patients prior to semipurification (Figure 1A). Biglycan recovery after all purification steps was linear in the range of $0.1-0.4 \mu \mathrm{g}$ and did not differ between healthy controls $(86 \% \pm 3 \%, n=3)$ and LN patients $(84 \% \pm 3 \%, n=3)$. Levels of circulating biglycan (Figure 1B) were elevated in the plasma of patients with LN $(5.0 \pm 1.1$-fold compared with controls, $n=5, P<0.05)$. In addition, high circulating biglycan concentrations were associated with albuminuria (Figure $1 \mathrm{C}$ and Table 1) and increased plasma levels of CXCL13 (Figure 1D and Table 1).
To examine renal accumulation of biglycan, immunohistochemical stainings were performed in kidney biopsy sections from patients with type IV LN $(n=12)$ and in normal kidneys $(n=5)$. Enhanced staining for biglycan was observed both in the glomerular and in the tubulointerstitial ECM in all cases of LN (Figure 1, E and F). The staining for biglycan was particularly pronounced in the peritubular space (Figure $1 \mathrm{~F}$ ) around and in some infiltrating mononuclear cells (Figure 1G). Clinical characteristics of healthy controls and patients with diffuse proliferative LN are provided in Table 1.

Enhanced plasma and renal biglycan expression in murine $L N$. To further study the role of biglycan in the evolution of LN, we used the MRL/lpr mouse model of SLE. The renal manifestation of SLE in $\mathrm{MRL} / \mathrm{lpr}$ mice is more pronounced in female animals and is first noticeable at 10 weeks of age (21). The progressive development of renal damage in this model with histological and immunologic abnormalities, closely resembling human LN, results in renal failure and death at an age of 24-32 weeks (21). Therefore, the majority of experiments were performed in 10- to 24-week-old female MRL/lpr mice. Similar to patients with LN, MRL/lpr mice displayed enhanced levels of circulating biglycan. Plasma biglycan levels in MRL/lpr mice increased progressively over time from nearly undetectable levels at 10 weeks of age over a $3.5 \pm 0.87$-fold increase $(n=5)$ at week 16 to a $6.7 \pm 1.6$-fold rise $(n=5)$ at week 24 (Figure $2 \mathrm{~A}$ ).

Next, we examined renal mRNA expression of biglycan in whole kidneys from MRL/lpr mice versus age-matched controls of the WT strain by quantitative RT-PCR (qRT-PCR). MRL/lpr mice at the age of 6 weeks displayed no differences in biglycan expression compared with WT controls (data not shown). However, already at week 10 , biglycan mRNA in the kidney from MRL/lpr mice was markedly elevated $(8.1 \pm 4.6$-fold over age-matched WT controls, $n=6$ in each group, $P<0.05$ ) (Figure $2 \mathrm{~B}$ ). With further disease progression, renal biglycan mRNA expression was $50 \pm 13$-fold increased at week 24 over WT controls $(n=6, P<0.05)$ (Figure 2B). These results were confirmed on the protein level both by Western blot analysis (Figure 2C) and immunohistochemistry (Figure 2D). Semipurification of proteoglycans from whole kidney homogenates followed by digestion with chondroitinase $\mathrm{ABC}$ and Western blotting of the biglycan protein core revealed progressive renal accumulation of biglycan over the course of nephritis in MRL/lpr mice (week 10: $1.5 \pm 0.2$-fold; week 16: $2.8 \pm 0.5$-fold; week 20: $4.5 \pm 0.9$-fold; week 24: $5.2 \pm 1.0$-fold; $n=3$ in each group, $P<0.05$ ). This effect was not due to an increase in total kidney weight in MRL/lpr mice during the course of LN (Tables 2 and 3), as similar results were obtained per mg of protein of kidney homogenate used for the proteoglycan isolation (data not shown). There was no age-dependent (10-24 weeks) difference in plasma levels, renal mRNA, nor protein expression of biglycan in WT mice; therefore, only 1 time point is shown for the WT controls (24-week-old WT mice; Figure 2, A-C). Immunostaining confirmed the enhanced deposition of biglycan in MRL/lpr mice during the course of LN (Figure 2D). Furthermore, the patterns of immunostaining for biglycan in the kidney were comparable (Figure 2D) to those observed in human LN (Figure 1C). Moreover, we found $2.2 \pm 0.2$-fold enhanced levels of circulating biglycan $(n=3$ in each group, $P<0.05)$ (Supplemental Figure 1A; supplemental material available online with this article; doi:10.1172/JCI42213DS1) in association with increased renal biglycan mRNA expression (Supplemental Figure 1B) and biglycan protein deposition (Supplemental Figure 1A) in New Zealand black/white-F1 (NZB/W-F1) hybrid mice, another murine model 
A

\begin{tabular}{|c|c|c|c|c|c|c|}
\hline \multicolumn{3}{|c|}{ MRL } & \multicolumn{3}{|c|}{ MRL/Ipr } & St \\
\hline Weeks & 24 & 10 & 16 & 20 & 24 & $0.3 \mu \mathrm{g}$ \\
\hline glycar & & & $4=$ & & & 20 \\
\hline
\end{tabular}

C

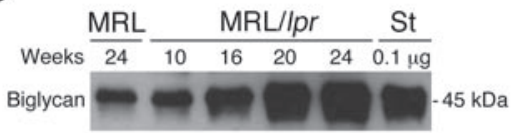

B

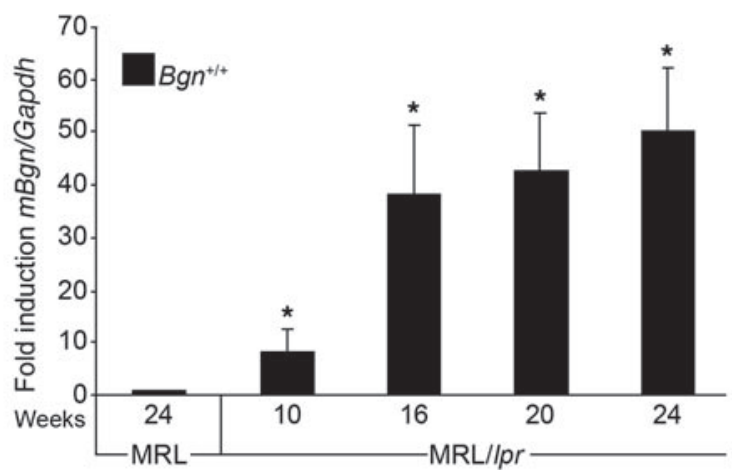

D
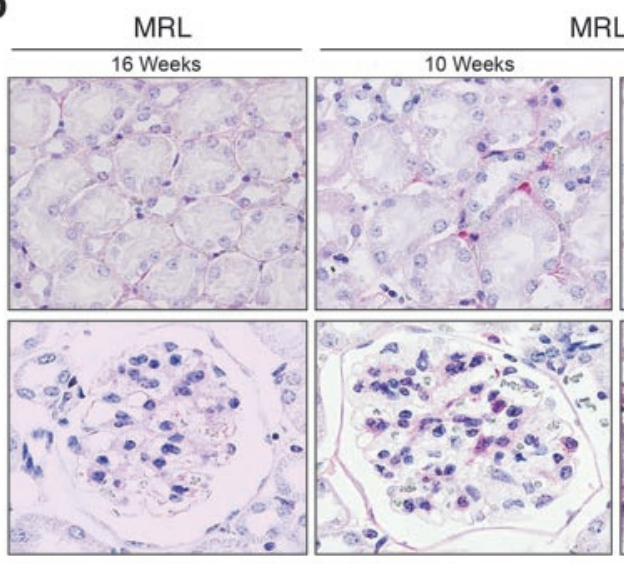

MRL/Ipr

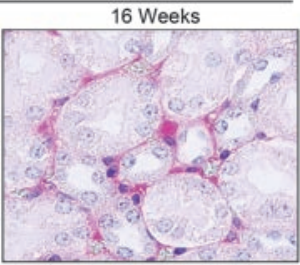

Negative control

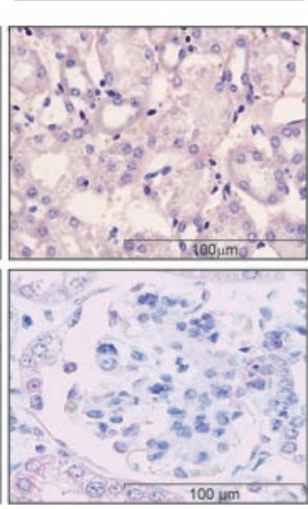

\section{Figure 2}

Overexpression of biglycan in the plasma and kidneys from lupus-prone mice (Bgn $\left.{ }^{+/+} \mathrm{MRL} / \mathrm{lpr}\right)$. (A and $\left.\mathbf{C}\right)$ Immunoblots for biglycan protein core after semipurification from plasma $(150 \mu \mathrm{l})(\mathbf{A})$ and kidneys $(150 \mu \mathrm{g})(\mathbf{C})$ from $B g n^{+/+} \mathrm{MRL} / \mathrm{lpr}$ mice with progressive $\mathrm{LN}$ versus $B g n^{+/+} \mathrm{MRL}$ control mice. Biglycan protein core $(0.3 \mu \mathrm{g}, \mathbf{A}$, or $0.1 \mu \mathrm{g}, \mathbf{C})$ was used as standard. (B) Enhanced biglycan mRNA expression in kidneys from 10-, 16-, 20-, and 24-week-old $B g n^{+/+} \mathrm{MRL} / \mathrm{lp}$ r mice versus the respective $B g n^{+/+} \mathrm{MRL}$ controls quantitated by TaqMan analysis after normalization to Gapdh (given as mean $\pm \mathrm{SD}$ ). Asterisks indicate statistical significance; $n=6$. ${ }^{*} P<0.05$. There was no age-dependent (10-24 weeks) difference in plasma levels (A), renal mRNA (B), and protein (C) expression of biglycan in MRL mice; therefore, only 1 time point is shown for the MRL controls. (D) Immunohistochemical analysis of biglycan expression patterns (APAAP, red) in the tubulointerstitium (upper panels) and glomeruli (lower panels) of renal tissue sections from 16-week-old control (Bgn $\left.{ }^{+/+} \mathrm{MRL}\right)$ and 10- and 16-week-old Bgn ${ }^{+/+} \mathrm{MRL} / / \mathrm{pr}$ mice. Counterstaining was done with Meyer's hematoxylin. The negative control was performed in renal tissue sections from 16-week-old Bgn+/+MRL/lpr mice by preadsorption of anti-biglycan antibody with purified mouse biglycan prior to the incubation with renal sections. Scale bars: $100 \mu \mathrm{m}$.

of SLE (22). Biglycan immunostaining patterns in NZB/W-F1 mice (Supplemental Figure 1C) were analogous to those found in LN patients (Figure 1C) and MRL/lpr mice (Figure 2D). Biglycan recovery after purification from plasma and kidneys was linear, without any differences between groups.

Biglycan deficiency improves clinical outcome in MRL/lpr mice. The association of elevated biglycan levels in plasma and kidney samples during the course of LN suggests involvement of biglycan in the pathogenesis of this condition in both humans and mice. To determine whether a lack of biglycan would influence the progression of LN, biglycan-deficient mice on an MRL/lpr background were generated $\left(B g n^{-/-} \mathrm{MRL} / \mathrm{lpr}\right)$ and compared with WT lupus mice $\left(B g n^{+/+} \mathrm{MRL} / \mathrm{lpr}\right)$. In all experiments, female mice at 10 to 24 weeks of age were analyzed. Clinical parameters for $B g n^{-/} \mathrm{MRL} / \mathrm{lpr}$, $B g n^{+/+} \mathrm{MRL} / \mathrm{lpr}$, and $B g n^{+/+} \mathrm{MRL}$ control mice are summarized in Tables 2 and 3 and in Supplemental Tables 1 and 2. There were no differences between $B g n^{+/} \mathrm{MRL}$ and $B g n^{-/-} \mathrm{MRL}$ mice over the whole experimental period; therefore, only parameters from $B g n^{+/+} \mathrm{MRL}$ were used for controls. As expected, the progression of
$\mathrm{LN}$ in $B g n^{+/+} \mathrm{MRL} / \mathrm{lpr}$ mice was associated with an increase in kidney weight and reduced creatinine clearance at 16 and 24 weeks of age compared with $\mathrm{Bgn}^{+/+} \mathrm{MRL}$ control animals (Table 3). Biglycan deficiency diminished this increment of kidney weight markedly and prevented the decline in renal function both in 16- and 24-week-old lupus mice (Table 3). The most striking difference caused by biglycan deficiency in lupus mice was a reduction in albuminuria over the whole experimental period (Figure 3A). Similar beneficial effects of biglycan deficiency were observed in male $\mathrm{MRL} / \mathrm{lpr}$ mice (data not shown). Thus, biglycan appears to play a crucial role in accelerating the progression of LN.

Persistently elevated levels of IgG and IgM class anti-dsDNA antibodies are a characteristic feature of SLE in humans and in MRL/ lpr mice (23). For this reason, we evaluated the influence of biglycan deficiency on the levels of total IgG and IgM as well as anti-dsDNA

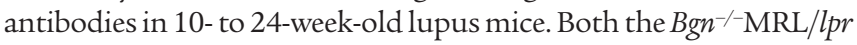
and $B g n^{+/+} \mathrm{MRL} / \mathrm{lpr}$ mice developed increasing levels of total IgG (Figure 3B), IgM (Figure 3C), and anti-dsDNA antibodies (Figure 3D) as compared with MRL controls. However, the increment of both 


\section{Table 2}

Characteristics of biglycan-transgenic $B g n^{+/+} \mathrm{MRL}$ and $B g n^{+/+} \mathrm{MRL} / / p r$ mice and their respective controls

Clinical parameter

\begin{tabular}{|c|c|c|c|c|c|c|c|}
\hline & & MRL & & & & $/ / p r$ & \\
\hline & $\mathrm{Bgn}^{+/+}$ & $\mathrm{Bgn}^{+/+} \mathrm{pLIVE}$ & $\mathrm{Bgn}^{+/+} \mathrm{hBGN}$ & $\mathrm{Bgn}^{+/+}$ & $\mathrm{Bgn}^{+/+} \mathrm{pLIVE}$ & $\mathrm{Bgn}^{+/+} \mathrm{h} B G N$ & Bgn $^{-1}$ \\
\hline Plasma crea (mg/dl) & $0.10 \pm 0.03$ & $0.09 \pm 0.06$ & $0.11 \pm 0.08$ & $0.08 \pm 0.05$ & $0.09 \pm 0.04$ & $0.11 \pm 0.07$ & $0.09 \pm 0.06$ \\
\hline $\mathrm{C}_{\text {crea }}(\mu \mathrm{l} / \mathrm{min})$ & $430 \pm 80$ & $420 \pm 90$ & $410 \pm 70$ & $390 \pm 90$ & $390 \pm 100$ & $350 \pm 80$ & $430 \pm 100$ \\
\hline Body weight (g) & $29 \pm 2.3$ & $29 \pm 1.6$ & $29 \pm 2.0$ & $30 \pm 0.92$ & $29 \pm 1.7$ & $29 \pm 1.1$ & $29 \pm 2.5$ \\
\hline Kidney weight (g) & $0.23 \pm 0.07$ & $0.24 \pm 0.06$ & $0.25 \pm 0.08$ & $0.25 \pm 0.03$ & $0.25 \pm 0.04$ & $0.37 \pm 0.05^{A}$ & $0.24 \pm 0.04$ \\
\hline Kidney/body weight ratio $\times 1000$ & $8.0 \pm 0.44$ & $8.2 \pm 0.53$ & $8.5 \pm 0.91$ & $8.6 \pm 0.48$ & $8.7 \pm 0.56$ & $13 \pm 1.0^{\mathrm{A}}$ & $8.4 \pm 1.5$ \\
\hline
\end{tabular}

Plasma creatinine was measured using the colorimetric microplate assay. The creatinine clearance was calculated from the plasma creatinine concentration and a timed urine sample. Kidney weights were determined and the kidney/body weight ratio was calculated for each animal. pLIVE, mice transiently transfected for 7 days with the pLIVE vector. hBGN, mice transiently transfected for 7 days with human biglycan inserted into the pLIVE vector. Values are given as mean $\pm \mathrm{SD}$ for $n=6$ per group. ${ }^{A} P<0.05 \mathrm{hBGN}$ MRL//pr versus age-matched $B g n^{+/+} \mathrm{MRL} / / p r$ mice. immunoglobulin classes was far less pronounced in biglycan-deficient lupus mice $\left(B g n^{-/-} \mathrm{MRL} / \mathrm{lpr}\right.$ ) as compared with $B g n^{+/+} \mathrm{MRL} / \mathrm{lpr}$ mice (Figure 3, B-D). There were no genotype- or age-dependent (10 to 24 weeks) differences in the plasma levels of total IgG, IgM, and anti-dsDNA antibodies in control animals $\left(B g n^{+/+} \mathrm{MRL}\right.$ and $\left.B g n^{-/-} \mathrm{MRL}\right)$. Only results from 24-week-old $B g n^{+/+} \mathrm{MRL}$ mice were used as controls (Figure 3, A-D). Furthermore, SLE-dependent enlargement of the spleen and lymph nodes, analyzed as the ratio of spleen weight or total weight of mediastinal, axillary, inguinal, and mesenteric lymph nodes to body weight, was markedly reduced in 10-, 16-, and 24-week-old Bgn ${ }^{-/-} \mathrm{MRL} / \mathrm{lpr}$ versus $B g n^{+/+} \mathrm{MRL} / \mathrm{lpr}$ mice (Supplemental Tables 1 and 2).

In vivo overexpression of soluble biglycan worsens albuminuria in $M R L /$ lpr mice. Upon tissue stress or injury, biglycan may be released from the ECM and subsequently turn into a soluble ligand capable of triggering a variety of cellular responses (1-3). To provide direct evidence that biglycan accelerates the progression of LN, mice of the MRL/lpr background overexpressing soluble human biglycan $(\mathrm{h} B G N)$ were generated. In particular, we were interested in the influence of biglycan at the onset of LN. Therefore, human biglycan was overexpressed in 9-week-old female mice and its effects were analyzed at day 7 following overexpression (10-week-old mice). Human biglycan cDNA was inserted into the BamHI/SacII site of the pLIVE (Liver In Vivo Expression) vector containing the mouse albumin promoter and injected intravenously into $B g n^{+/+} \mathrm{MRL} / \mathrm{lpr}\left(\mathrm{h} B G N \mathrm{MRL} / \mathrm{lpr}\right.$ ) and $B g n^{+/+} \mathrm{MRL}(\mathrm{h} B G N$ MRL) mice. An empty pLIVE vector was used to generate $B g n^{+/+} \mathrm{MRL} / \mathrm{lpr}$ (pLIVE MRL/lpr) and $B g n^{+/+}$MRL (pLIVE MRL) control mice. $B g n^{+/+} \mathrm{MRL} / \mathrm{lpr}$ and $B g n^{+/+} \mathrm{MRL}$ injected only with vehicle were used for additional controls (Figure 4, A-C). In this model, liver-specific expression of $\mathrm{h} B G N \mathrm{mRNA}$, circulating levels, and deposition of human biglycan protein in the kidneys, lungs, heart, and skeletal muscle were observed between 1 and 20 days after injection of $\mathrm{h} B G N$ pLIVE (data not shown). Because $\mathrm{h} B G N$ mRNA in the liver as well as circulating human biglycan levels peak at day 7 after transfection, followed by a steady decline, we chose this time point of transfection as the optimal experimental period.

Using RT-PCR with subsequent digestion by SacI, hepatic expression of the hBGN gene was detected at day 7 in $\mathrm{h} B G N$ MRL/lpr and hBGN MRL mice (Figure 4A). As expected, hBGN mRNA expression was liver specific and did not occur in other organs (kidneys, lungs, heart, and skeletal muscles were all negative; data not shown). Due to a single SacI restriction site present in the human but not in the murine biglycan gene sequence, digestion of amplified cDNA resulted in 2 fragments ( $272 \mathrm{bp}$ and $165 \mathrm{bp}$ ) of human and 1 fragment (428 bp) of murine origin (Figure $4 \mathrm{~A})$. The lower intensity of the murine biglycan band in transfected livers (Figure 4A) was not due to suppressed endogenous biglycan but was probably caused by reduced primer availability, as human (bp 573-1001) and murine biglycan (bp 585-1013) sequences show $90 \%$ homology in their cDNA. Using primers distinguishing endogenous from human biglycan, as indicated in

\section{Table 3}

Characteristics of $B g n^{+/+} \mathrm{MRL}, \mathrm{Bgn}^{+/+} \mathrm{MRL} / / p r$, and $B g n^{-/-} \mathrm{MRL} / / p r$ mice at 16 and 24 weeks of age

Clinical parameter

\begin{tabular}{lccc} 
& MRL & \multicolumn{2}{c}{ MRL/Ipr } \\
& $\boldsymbol{B g n}^{+/+}$ & Bgn $^{+/+}$ & Bgn $^{-/}$ \\
Plasma crea $(\mathrm{mg} / \mathrm{dl})$ & $0.10 \pm 0.02$ & $0.20 \pm 0.03^{\mathrm{A}}$ & $0.15 \pm 0.05$ \\
$\mathrm{C}_{\text {crea }}(\mu \mathrm{l} / \mathrm{min})$ & $420 \pm 60$ & $270 \pm 40^{\mathrm{A}}$ & $360 \pm 40^{\mathrm{B}}$ \\
Body weight $(\mathrm{g})$ & $40 \pm 1.6$ & $43 \pm 1.7$ & $42 \pm 1.2$ \\
Kidney weight $(\mathrm{g})$ & $0.33 \pm 0.03$ & $0.57 \pm 0.08^{\mathrm{A}}$ & $0.36 \pm 0.05^{\mathrm{B}}$ \\
Kidney/body weight ratio $\times 1000$ & $8.1 \pm 0.95$ & $13 \pm 1.0^{\mathrm{A}}$ & $8.4 \pm 1.1^{\mathrm{B}}$ \\
\hline
\end{tabular}

16 week old
Plasma creatinine (crea) was measured using the colorimetric microplate assay. The creatinine clearance $\left(\mathrm{C}_{\text {crea }}\right)$ was calculated from the plasma creatinine concentration and a timed urine sample. Kidney weights were determined and the kidney/body weight ratio was calculated for each animal. Values are given

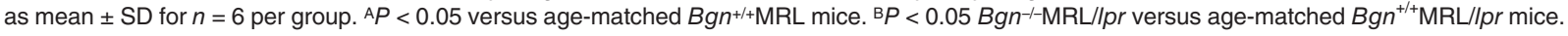

\section{4 week old}

\begin{tabular}{ccc} 
MRL & \multicolumn{2}{c}{ MRL/Ipr } \\
Bgn $^{+/+}$ & Bgn $^{+/+}$ & Bgn $^{-/}$ \\
$0.11 \pm 0.08$ & $0.28 \pm 0.05^{\mathrm{A}}$ & $0.16 \pm 0.07^{\mathrm{B}}$ \\
$400 \pm 70$ & $170 \pm 60^{\mathrm{A}}$ & $300 \pm 60^{\mathrm{B}}$ \\
$43 \pm 2.1$ & $45 \pm 5.4$ & $46 \pm 4.4$ \\
$0.38 \pm 0.01$ & $0.70 \pm 0.08^{\mathrm{A}}$ & $0.50 \pm 0.04^{\mathrm{A}, \mathrm{B}}$ \\
$9.0 \pm 0.44$ & $16 \pm 1.7^{\mathrm{A}}$ & $10 \pm 0.38^{\mathrm{B}}$
\end{tabular}



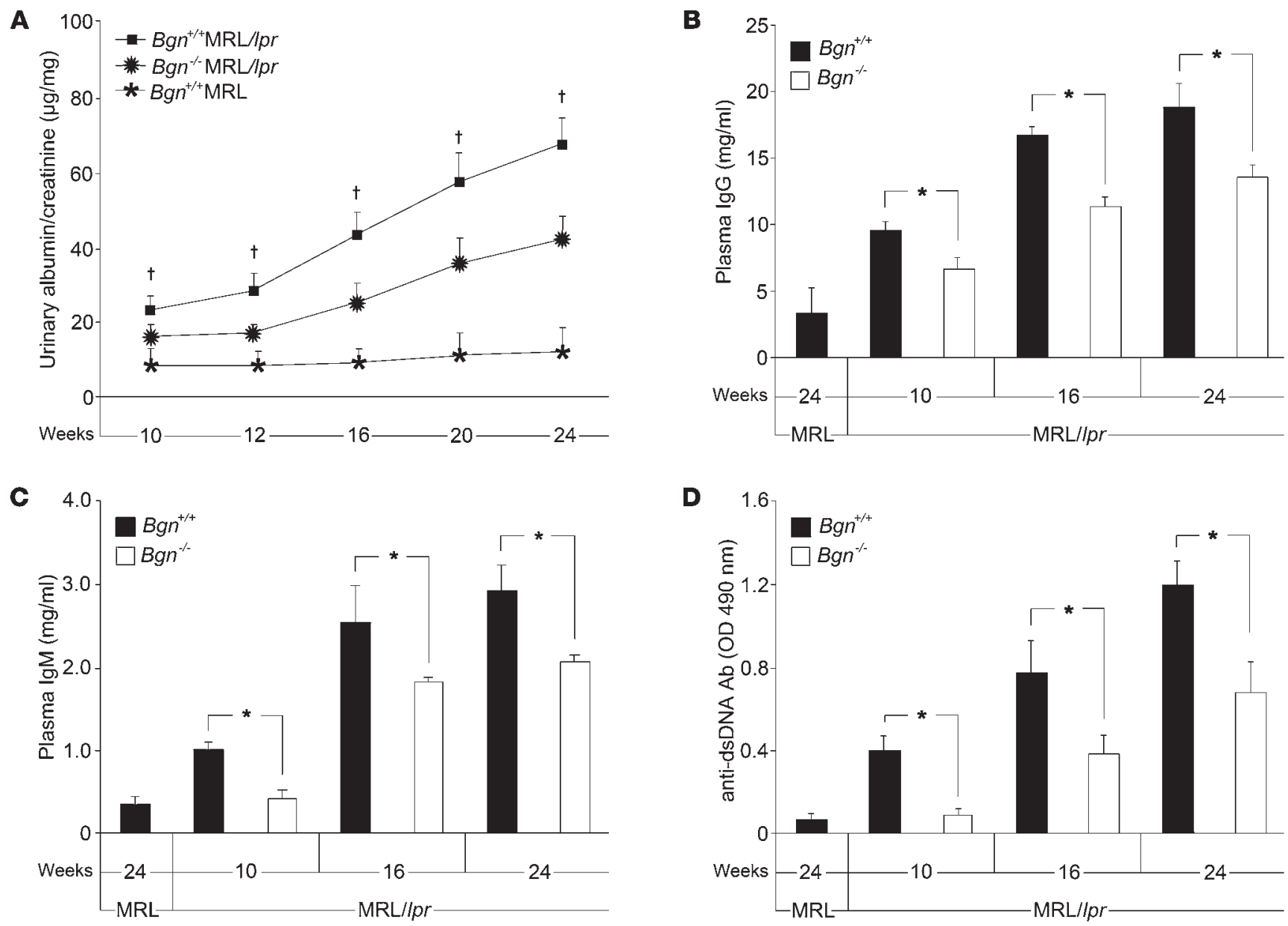

Figure 3

Biglycan deficiency in LN is associated with lower albuminuria, plasma IgG, IgM, and anti-dsDNA antibody levels. (A) Urinary albumin/creati-

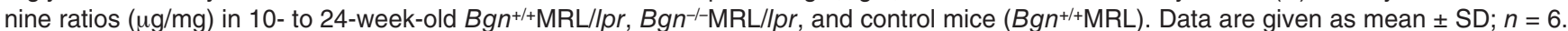

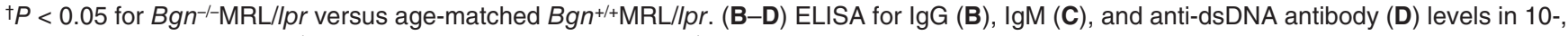
16-, and 24-week-old $B g n^{-1-M R L / l p r ~ v e r s u s ~ a g e-m a t c h e d ~} B g n^{++} \mathrm{MRL} / \mathrm{lp} r$ mice; mean $\pm \mathrm{SD}, n=6 .{ }^{*} P<0.05$. As there were no genotypic or agedependent (10-24 weeks) differences in plasma levels of total $\lg$ (B), IgM (C), and anti-dsDNA antibodies (D) in control animals (Bgn ${ }^{+/+M R L}$

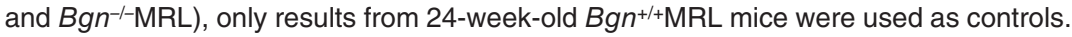

Methods, equal expression of mouse biglycan was detected in liv-

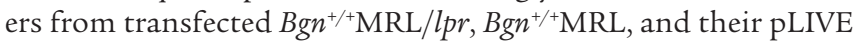
controls (data not shown). Induction of human biglycan expression increased the plasma levels of biglycan $7.1 \pm 1.5$-fold vs. noninjected animals of both genotypes $(n=6$ in each group, $P<0.05)$ (Figure 4B) as well as renal biglycan content (hBGN MRL/lpr: $6.2 \pm 0.7$-fold vs. pLIVE MRL/lpr; hBGN MRL: $6.8 \pm 2.3$-fold vs. pLIVE MRL; $n=6$ in each group, $P<0.05$ ) (Figure 4C). Biglycan recovery following purification from plasma and kidney tissue was linear and showed no differences between the experimental groups. As anti-biglycan antibodies recognize both human and murine biglycan proteins, differentiation between human and endogenous biglycan was not possible (Figure 4, B and C). However, a marked increase of circulating biglycan as well as renal biglycan protein in $\mathrm{h} B G N \mathrm{MRL} / l_{p r}$ versus $\mathrm{PLIVE} \mathrm{MRL/lpr} \mathrm{mice}$ and in $\mathrm{h} B G N$ MRL versus pLIVE MRL clearly indicated sufficient transfection. Mice transfected with hBGN did not develop antihuman biglycan antibodies at days 1,4 , and 7 following h $B G N$ pLIVE injection (measured by ELISA; data not shown).
Importantly, elevated levels of soluble biglycan were associated with enhanced albuminuria in $\mathrm{h} B G N \mathrm{MRL} / \mathrm{lp} r$ versus $\mathrm{MRL} / \mathrm{lpr}$ mice (Figure 4D), providing evidence that biglycan worsens LN. Transfection with $\mathrm{h} B G N$ did not cause albuminuria in $\mathrm{h} B G N \mathrm{MRL}$ controls (Figure 4D). Variations in albuminuria levels were controlled by measuring urinary albumin in individual mice before and after day 7 of the transfection period (Figure 4D). Additionally, kidney and lymph node weights were increased in $\mathrm{h} B G N$ MRL/lprversus MRL/lpr mice (Table 2 and Supplemental Table 1). Other clinical parameters (Table 2 and Supplemental Table 1) were unaffected at day 7 of biglycan overexpression. In particular, plasma levels of total IgG, IgM, and anti-dsDNA antibodies were not influenced by the enhanced levels of circulating biglycan in lupus mice (MRL/lpr: $9.5 \pm 0.7 \mathrm{mg} / \mathrm{ml}, 1.0 \pm 0.08 \mathrm{mg} / \mathrm{ml}$, and $0.38 \pm 0.13$ OD; pLIVE MRL/lpr: $8.6 \pm 0.9 \mathrm{mg} / \mathrm{ml}, 0.99 \pm 0.12 \mathrm{mg} / \mathrm{ml}$, and $0.36 \pm 0.08 \mathrm{OD} ; \mathrm{h} B G N \mathrm{MRL} / \mathrm{lpr}: 11 \pm 1.4 \mathrm{mg} / \mathrm{ml}, 1.4 \pm 0.11 \mathrm{mg} / \mathrm{ml}$, and $0.37 \pm 0.18 \mathrm{OD}, n=6, P>0.05$ for IgG, IgM, and anti-dsDNA antibodies respectively). Results similar to those described above were observed at day 14 following transfection (data not shown). 
A

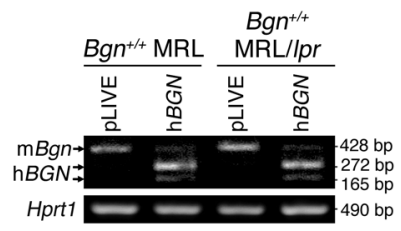

B

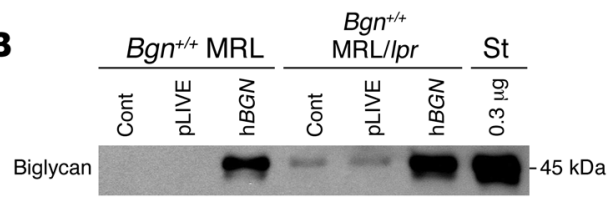

C

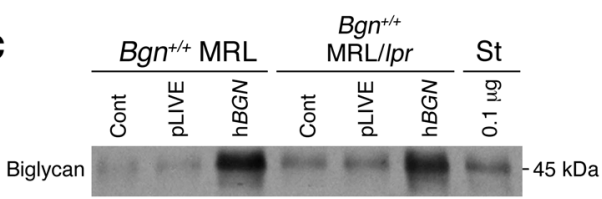

D

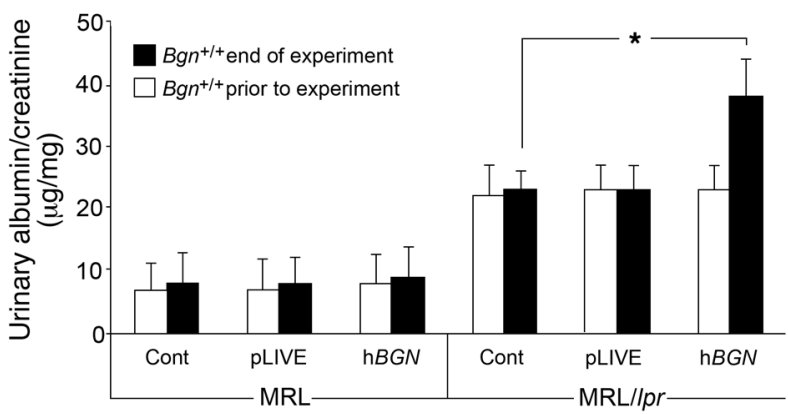

Biglycan-dependent worsening of renal histopathology in MRL/lpr mice. We also examined the impact of biglycan on renal histopathology in 10-week-old (onset of pathological alterations in the kidney) female MRL/lpr mice either lacking (Bgn ${ }^{-/} \mathrm{MRL} / \mathrm{lpr}$ ) or overexpressing (hBGN MRL/lpr) biglycan versus their WT (Bgn $n^{+/} \mathrm{MRL} /$ $l p r)$ lupus counterparts. Additionally, the influence of biglycan deficiency on the development of renal pathology was analyzed in 16- and 24-week-old $B g n^{-/-} \mathrm{MRL} / \mathrm{lpr}$ versus $B g n^{+/+} \mathrm{MRL} / \mathrm{lpr}$ mice. Ageand sex-matched $\mathrm{Bgn}^{+/+}, \mathrm{Bg} n^{-/-}$, pLIVE, and hBGN mice with MRL background were used as respective controls. The severity of renal lesions (glomerular cellularity with infiltrating leukocytes, mesangial matrix expansion, crescent formation, interstitial mononuclear cell infiltrates in the medulla and cortex, hyaline deposits, fibrinoid necrosis, and tubular atrophy) was graded in PAS stainings as 0 to 3 (Figure 5) (24). In kidneys from 10-week-old $B g n^{+/+} \mathrm{MRL} /$ lpr mice, focal glomerular cell proliferation and perivascular mononuclear cells were observed occasionally (Figure 5A). In contrast, there were no apparent renal changes in $B g n^{-/-\mathrm{MRL} /} / \mathrm{pr}$ mice (Figure $5 \mathrm{~A}$ ). Conversely, 7 days of biglycan overexpression in $\mathrm{h} B G N \mathrm{MRL} / \mathrm{lpr}$ mice slightly accelerated glomerular cell proliferation and accumulation of mesangial matrix and markedly increased the number of periglomerular, perivascular, and interstitial mononuclear cells (Figure 5A). Perivascular and interstitial mononuclear cells were observed, however, to a much lesser extent in kidneys from hBGN MRL mice as well (Figure 5B). Transfection with the empty pLIVE vector had no influence on renal morphology in MRL and MRL/lpr mice (Figure $5 \mathrm{~B}$ ). Importantly, biglycan deficiency markedly prevented progression of renal histological changes in MRL/lpr mice throughout

\section{Figure 4}

Overexpression of soluble human biglycan (7 days) in the liver from transiently transgenic $B g n^{+/+} \mathrm{MRL}$ and $\mathrm{Bgn}^{+/+} \mathrm{MRL} / / p r$ mice resulted in the presence of human biglycan in plasma and kidneys and caused enhanced albuminuria. (A) Representative RT-PCR from total RNA extracted from the liver of $\mathrm{Bgn}^{+/+} \mathrm{MRL}$ and $\mathrm{Bgn}^{+/+} \mathrm{MRL} / \mathrm{lp}$ r mice transiently transfected with the pLIVE expression vector plasmid (pLIVE) and pLIVE vector with the inserted human biglycan sequence (hBGN pLIVE). Due to a single Sacl restriction site present in the human biglycan gene sequence, digestion of amplified cDNA with Sacl resulted in 2 fragments (272 bp and $165 \mathrm{bp}$ ) of human ( $\mathrm{hBGN}$ ) compared with a single fragment (428 bp) of murine ( $\mathrm{mBgn}$ ) origin. Mouse Hprt1 was used as a housekeeping gene. ( $\mathbf{B}$ and $\mathbf{C}$ ) Western blots for biglycan protein core after semipurification of proteoglycans from plasma (B) and kidney (C) from $B g n^{+/+} \mathrm{MRL}$ and $\mathrm{Bgn}^{+/+} \mathrm{MRL} / \mathrm{lpr}$ mice transiently transfected with hBGN, empty-vector-injected (pLIVE), and control solvent-injected (Cont) mice. Biglycan recovery following purification from plasma and kidneys was linear and varied by $85 \% \pm 6 \%$ for all groups. Standards contained $0.3 \mu \mathrm{g}$ (B) or $0.1 \mu \mathrm{g}$ (C) of biglycan that was digested with chondroitinase ABC. (D) Urinary albumin/creatinine ratios $(\mu \mathrm{g} / \mathrm{mg})$ in 9-week-old $B g n^{+/+} \mathrm{MRL}$ and $\mathrm{Bgn}^{+/+} \mathrm{MRL} / / \mathrm{pr}$ mice prior to and after 7 days of overexpressing human biglycan (mean $\pm S D$ ). Asterisk indicates statistical significance; $n=6$. ${ }^{*} P<0.05$. the whole experiment (Figure 5, A and B). There was no difference in renal histology between $B g n^{+/+} \mathrm{MRL}$ and $B g n^{-/-} \mathrm{MRL}$ mice. Thus, the worsening of renal histopathology in MRL/lpr mice appears to be strongly modulated by biglycan.

Effects of biglycan on the number of infiltrating macrophages and T cells and their chemoattractants (MCP-1, RANTES, and MIP-1 $\alpha$ ) in kidneys from $M R L / l p r$ mice. To further characterize the influence of biglycan on the course of LN, total infiltrating mononuclear cells, F4/80positive macrophages, and CD3-positive $\mathrm{T}$ cells were counted in renal sections from MRL and MRL/lpr mice either lacking or overexpressing biglycan versus their WT counterparts (Table 4). Biglycan deficiency caused a marked reduction in the total number of mononuclear cells, macrophages, and T cells (periglomerular, interstitial, and perivascular) (Table 4 and data not shown). In contrast, biglycan overexpression enhanced the total number of mononuclear cells, macrophages, and T cells (Table 4). There was no difference in the number of total infiltrating mononuclear cells, macrophages, and T cells between $B g n^{+/+} \mathrm{MRL}$ and $B g n^{-/-}$MRL mice.

In the same groups of animals, we also determined whether biglycan would influence renal and circulating levels of selected macrophage and T cell chemoattractants MCP-1 (CCL2), RANTES (CCL5), and MIP-1 $\alpha$ (CCL3). Biglycan deficiency led to lower renal (Figure 6) and plasma levels (Table 5) of MCP-1 (Figure $6 \mathrm{~A}$ and Table 5), RANTES (Figure 6B and Table 5), and MIP- $1 \alpha$ (Figure 6C and Table 5) throughout the experiment. Furthermore, overexpression of biglycan was associated with enhanced renal and circulating levels of all 3 chemokines both in MRL and $\mathrm{MRL} / \mathrm{lpr}$ mice. There was no difference in MCP-1, RANTES, and 
MIP-1 $\alpha$ levels between $B g n^{+/+} \mathrm{MRL}$ and $B g n^{-/-} \mathrm{MRL}$ mice. TNF- $\alpha$ expression has been shown to be directly regulated by biglycan in macrophages (2). In fact, TNF- $\alpha$ levels in kidneys (Figure 6D) and plasma (Table 5) were dependent on biglycan gene expression and revealed patterns similar to those observed for MCP-1, RANTES, and MIP- $1 \alpha$ in all experimental groups. Thus, biglycan appears to be a regulator of various proinflammatory chemokines and cytokines, thereby influencing the number of infiltrating mononuclear cells.

Effects of biglycan on the levels of mature $I L-1 \beta$, active caspase-1, and $N L R P 3$ in kidneys from MRL/lpr mice. Next, we determined whether the biglycan-induced synthesis of pro-IL-1 $\beta$ and NLRP3/caspase-1dependent processing from the proform to mature IL-1 $\beta$ (3) might influence the progression of LN in MRL/lpr mice. Renal pro-Il1B (Figure 7A) and Nlrp3 (Figure 7B) mRNAs were progressively overexpressed in kidneys of 10-, 16-, and 24-week-old MRL/lpr mice. This was associated with enhanced renal levels of active caspase-1 (Figure 7, C and E) and mature IL-1 $\beta$ (Figure 7F). Biglycan deficiency resulted in a reduction of pro-Il1B (Figure 7A) and Nlrp3 (Figure 7B) mRNA expression as well as in decreased levels of active caspase- 1 (Figure 7, C and E) and mature IL-1 $\beta$ (Figure 7F) over the whole experimental period. Conversely, transient overexpression of soluble biglycan led to elevated expression of pro-Il1B (Figure $7 \mathrm{~A}$ ) and $N \operatorname{lrp3}$ (Figure 7B) in association with higher levels of active caspase-1 (Figure 7, D and E) and mature IL-1 $\beta$ (Figure 7F) in $\mathrm{MRL} / \mathrm{lpr}$ mice kidneys. IL-1 $\beta$ plasma levels revealed the same biglycan gene expression-dependent pattern (Table 5). Thus, biglycan appears to be a critical regulator of pro-Il1B expression and NLRP3/ caspase- 1 dependent maturation of IL- $1 \beta$ in LN. It is noteworthy that overexpression of soluble biglycan enhanced renal pro-Il1B (Figure 7A) and Nlrp3 (Figure 7B) mRNAs and active caspase-1 (Figure 7, D and E) as well as mature IL-1 $\beta$ in MLR mouse kidneys (Figure 7F) and plasma (Table 5). There was no difference in any of those parameters between $B g n^{-/-} \mathrm{MRL}$ and $B g n^{+/} \mathrm{MRL}$ mice.

Biglycan-mediated alteration of $B$ cell numbers and $B 1 / B$ cell ratio in kidneys from MRL/lpr mice. As the levels of total IgG, IgM, and antidsDNA antibodies were reduced in the plasma from $B g n^{-1-} \mathrm{MRL} / \mathrm{lpr}$ compared with $B g n^{+/+} \mathrm{MRL} / \mathrm{lpr}$ mice (Figure 3, C and D), we determined whether biglycan might influence the number of renal $B$ cells in LN. Leukocytes were isolated from whole kidneys of MRL and MRL/lpr mice (biglycan deficient or overexpressing vs. WT animals), counted, and processed for FACS analysis. The number of $\mathrm{B}$ cells (CD19 positive) was markedly reduced in kidneys from $B g n^{-/-} \mathrm{MRL} / l_{p r}$ versus $B g n^{+/+} \mathrm{MRL} / \mathrm{lpr}$ mice (Table 6 and Supplemental Figure 2A). Next, CD19-positive cells were selected by MicroBeads and MACS Technology followed by FACS analysis of the B1 subpopulation (cells positive for CD19 and CD5) (Table 6 and Supplemental Figure 2B). As expected, the numbers of total B cells and of the B1 subpopulation increased progressively in kidneys from MRL/lpr mice during the course of LN (Table 6 and Supplemental Figure 2B). Importantly, biglycan deficiency not only caused a reduction of $\mathrm{B}$ cells but also diminished the B1/total B cell ratio in kidneys from MRL/lpr mice at 10, 16, and 24 weeks of age (Table 6). Conversely, overexpression of biglycan enhanced the total number of B cells and increased the percentage of the B1 subpopulation in kidneys from 10-week-old MRL/lpr mice (Table 6). There was no difference in the total number of infiltrating cells and in the number of B or B1 cells between $B g n^{+/+} \mathrm{MRL}$ and $B g n^{-/-} \mathrm{MRL}$ mice. Thus, biglycan appears to play a role in the regulation of the number and composition of the B cell population in LN. In agreement with results obtained from the staining of renal sections (Table 4), the total number of isolated mononuclear cells from kidneys of $\mathrm{Bgn}^{-1-}$ $\mathrm{MRL} / \mathrm{lpr}$ mice was lower compared with those from $B g n^{+/} \mathrm{MRL} / \mathrm{lpr}$ mice (data not shown).

Effects of biglycan expression on the B cell chemoattractant CXCL13 in kidneys, plasma, and resident peritoneal macrophages from $M R L / l p r$ mice. As the B1 subpopulation is preferentially attracted by CXCL13 (BLC-1) in NZB/W-F1 lupus mice (25), we determined whether the biglycan genotype might have an impact on renal expression of CXCL13 in MRL/lpr and MRL mice. Expression of the Cxcl13 mRNA (qRT-PCR) was increasingly upregulated in $\mathrm{MRL} / \mathrm{lpr}$ kidneys (Figure 8A). Biglycan deficiency resulted in a reduction of Cxcl13 mRNA expression over the whole experimental period (Figure 8A). In contrast, Cxcl13 mRNA was enhanced in kidneys of biglycan-overexpressing MRL/lpr and MRL mice (Figure 8A). These results were further confirmed on the protein level (ELISA), as the kidney (Figure 8B) and plasma (Figure 8C) CXCL13 levels revealed a similar biglycan-dependent pattern. The renal expression of Cxcr 5 mRNA (qRT-PCR), the receptor for CXCL13 located on B cells $(26,27)$, was downregulated in $B g n^{-/} \mathrm{MRL} / \mathrm{lpr}$ (week 10, 16 , and 24) and upregulated in hBGN MRL/lpr (10 weeks) mice compared with the respective WT animals (Figure 8D). There were no differences between $B g n^{+/+} \mathrm{MRL}$ and $B g n^{-/-} \mathrm{MRL}$ mice for any of the parameters mentioned above. In addition, in 16-week-old NZB/W-F1 mice, increased levels of circulating and renal biglycan (Supplemental Figure 1) were associated with a $2.2 \pm 0.6$-fold and a $3.9 \pm 1.4$-fold rise in CXCL13 levels in plasma and kidneys, respectively ( $n=4$ in each group, $P<0.05)$.

Next, we addressed the question of whether expression of CXCL13 in resident peritoneal macrophages, which are the major source of CXCL13 in the peritoneal cavity $(28,29)$, is influenced by biglycan deficiency in MRL/lpr mice. Resident macrophages were collected by peritoneal lavage from 16-week-old $B g n^{+/+} \mathrm{MRL} / \mathrm{lpr}$ and $\mathrm{Bgn} n^{-/-} \mathrm{MRL} / \mathrm{lpr}$ mice and their respective controls. Cxcl13 mRNA levels in macrophages and chemokine levels in cell supernatants were measured after 12 hours of culture under serum-free conditions without stimulation. Cxcl13 mRNA expression was 30.6 \pm 4.6 -fold ( $n=6$ in each group, $P<0.05)$ higher in macrophages from $B g n^{+/+} \mathrm{MRL} / \mathrm{lpr}$ compared with $\mathrm{Bgn} n^{++} \mathrm{MRL}$ mice, resulting in enhanced secretion of the CXCL13 protein $\left(B g n^{+/+} \mathrm{MRL} / \mathrm{lpr}: 750 \pm 267 \mathrm{pg} / \mathrm{ml}\right.$ vs. $B g n^{+/+} \mathrm{MRL}$ : $5.8 \pm 3.2 \mathrm{pg} / \mathrm{ml} ; n=6$ in each group, $P<0.05$ ) (Figure 8F). In contrast, biglycan-deficient macrophages revealed only moderate enhancement of Cxcl13 mRNA $(2.9 \pm 0.52$-fold, $n=6, P<0.05)$ and of secreted CXCL13 protein $(15 \pm 8.5 \mathrm{pg} / \mathrm{ml}, n=6, P<0.05)$ compared with their respective controls (Figure 8, E and $\mathrm{F}$ ).

Biglycan triggers CXCL13 expression in resident peritoneal macrophages and spleen dendritic cells via interaction with TLR2 and TLR4 in a ROS-dependent manner. Macrophages and dendritic cells are major sources of CXCL13 in inflammatory diseases $(25,28,30)$. To show that biglycan directly regulates expression of CXCL13, we incubated resident peritoneal macrophages and spleen dendritic cells from C57BL/ 6 mice with human biglycan $(4 \mu \mathrm{g} / \mathrm{ml}$, 4 hours). Stimulation with biglycan resulted in upregulation of Cxcl13 mRNA (qRT-PCR) in dendritic cells (Figure 9A) and macrophages (Figure 9C) as well as in enhanced levels of CXCL13 protein in culture supernatants from both cell types (Figure 9, B and D). Furthermore, stimulation of CXCL13 was inhibited by biglycan-neutralizing antibodies and could not be mimicked by TNF- $\alpha$ or by IL-1 $\beta, 2$ downstream effectors of biglycan. Neither the biglycan protein core nor biglycan-derived glycosaminoglycan 
A
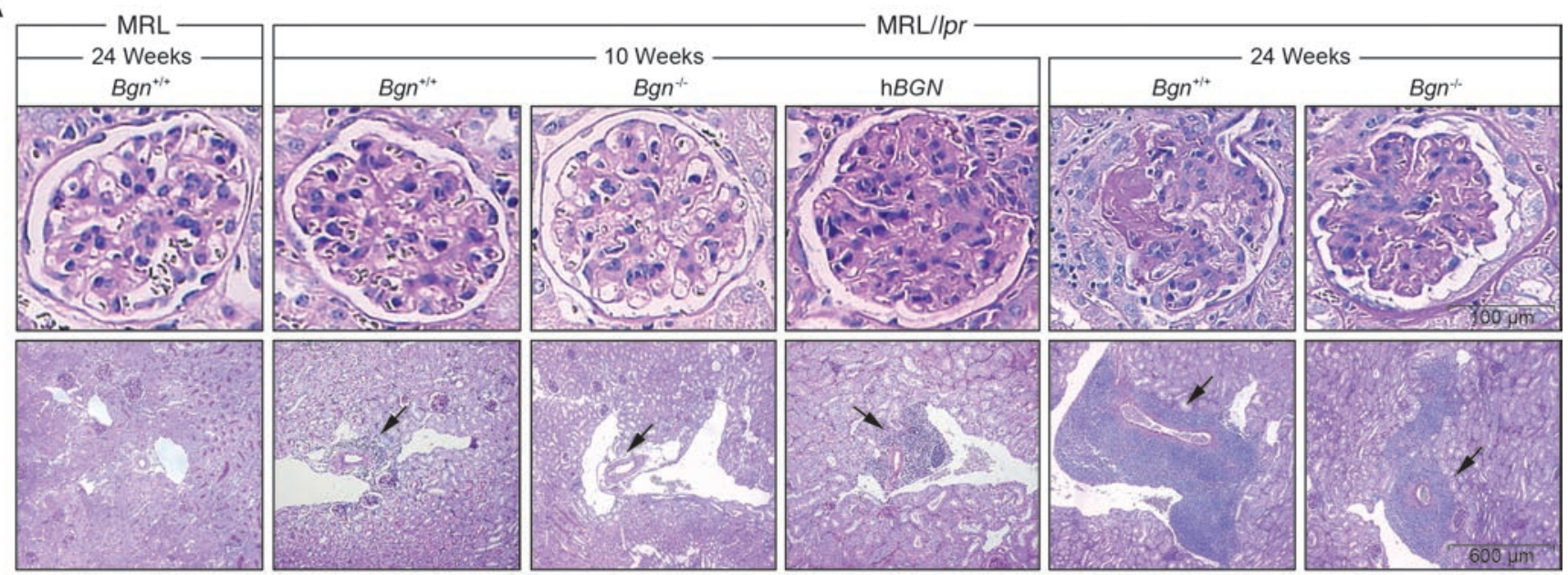

B

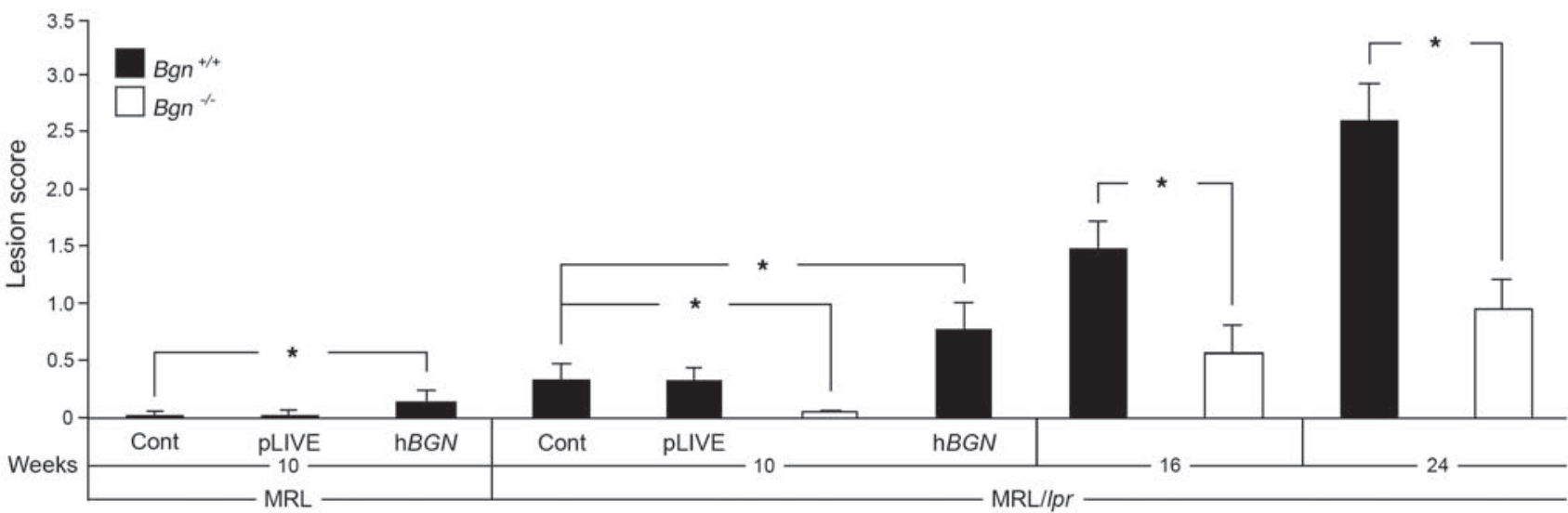

\section{Figure 5}

Effects of biglycan deficiency and overexpression on renal histopathology of lupus prone mice and their respective controls. (A) PAS-stained kidney sections showing glomeruli (upper panels) and tubulointerstitium (lower panels) from 10-week-old $B g n^{+/+} \mathrm{MRL}, B g n^{+/+} \mathrm{MRL} / / p r, B g n^{-/}$ $\mathrm{MRL} / / \mathrm{pr}$, and biglycan-overexpressing (hBGN) mice and their respective controls as well as from 24-week-old $B g n^{-/} \mathrm{MRL} / \mathrm{pr}$ and $B g n^{+/+} \mathrm{MRL} / / p r$ mice. There was no difference in renal histology between $B g n^{++} \mathrm{MRL}$ and $B g n^{-/} \mathrm{MRL}$ mice. 24-week-old $B g n^{+/+} \mathrm{MRL}$ is shown as a control. The arrows indicate perivascular areas of infiltrating cells. Scale bars indicate the respective magnifications. (B) Quantification of the renal histologi-

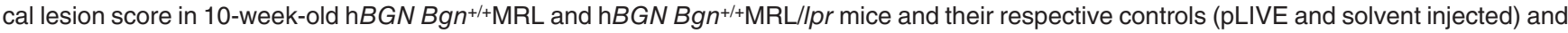
in 10-, 16-, and 24-week-old $B g n^{-/-M R L / I p r}$ and $B g n^{+/} \mathrm{MRL} / / p r$ mice. The renal lesion scores of at least 6 mice of each group were graded as described in Methods. Data are given as mean \pm SD. Asterisks indicate statistical significance; $n=6 .{ }^{*} P<0.05$.

side chains (obtained by $\beta$ elimination) (2) alone affected CXCL13 levels, suggesting that both core protein and glycosaminoglycan chains are necessary for the stimulation of macrophages and spleen dendritic cells (data not shown).

In macrophages, biglycan has been shown to induce secretion of TNF- $\alpha$ and MIP-2 via TLR2/4 $(2,3)$. Therefore, by using resident peritoneal macrophages and spleen-derived dendritic cells from $\mathrm{Tl} \mathrm{2}^{-/-}$, Tlr4 ${ }^{-/}$, and Tlr2 ${ }^{--}$Tlr4-m (Tlr4-m mice with a TLR4 gene point mutation) mice, we determined whether biglycan-triggered CXCL13 expression is TLR dependent. In fact, biglycan-mediated CXCL13 expression and protein secretion from dendritic cells (Figure 9, A and B) and macrophages (Figure 9, C and D) was reduced in the absence of either TLR2 or TLR4 and completely abolished in TLR2-/-TLR4-M deficient cells (Figure 9). Thus, biglycan is capable of triggering CXCL13 expression via TLR2 and TLR4 in dendritic cells and macrophages.

To gain further insights into the regulation of CXCL13, we determined whether ROS, a downstream mediator of biglycan/
TLR2/4 signaling (3), is involved in biglycan-mediated induction of CXCL13. In fact, N-acetylcysteine (NAC), an inhibitor of ROS and diphenyleneiodonium (DPI), an inhibitor of NADPH oxidase and other flavin-containing oxidases, partially reduced biglycanmediated secretion of CXCL13 from macrophages (Figure 9E). In contrast, P2X7R, ASC and caspase-1 deficiencies had no influence on biglycan-mediated stimulation of CXCL13 (Figure 9F) but reduced the levels of mature IL-1 $\beta$ in affected macrophages as expected (3) (data not shown). Thus, biglycan stimulates CXCL13 in a TLR2/4- and ROS-dependent manner and independently of $\mathrm{P} 2 \mathrm{X} 7 \mathrm{R}$ and the inflammasome.

In vivo prooffor the involvement of TLR2 and TLR4 in biglycan-mediated induction of CXCL13, TNF- $\alpha, I L-1 \beta$, RANTES, MCP-1, MIP-1 $\alpha$, and mononuclear cell enhancement. Transient overexpression of soluble biglycan was potent enough to induce renal and plasma levels of CXCL13 (Figure 8), TNF- $\alpha$, IL-1 $\beta$, RANTES, MCP-1, and MIP-1 $\alpha$ (Figures 6 and 7, and Table 5) with a corresponding enhancement 


\section{Table 4}

Quantification of infiltrating mononuclear cells in kidneys from $\mathrm{Bgn}^{+/+} \mathrm{MRL}$ and MRL/Ipr mice lacking or overexpressing biglycan and their respective controls (immunohistochemical analysis)

\begin{tabular}{|c|c|c|c|c|c|c|c|}
\hline \multicolumn{2}{|c|}{ Genotype } & \multicolumn{2}{|c|}{ Mononuclear cells } & \multicolumn{2}{|c|}{ Macrophages } & \multicolumn{2}{|c|}{ T Iymphocytes } \\
\hline & & $\begin{array}{c}\text { Total cell } \\
\text { number/hpf }\end{array}$ & $\begin{array}{l}\text { Perivascular } \\
\text { score }\end{array}$ & $\begin{array}{l}\text { Total cell } \\
\text { number/hpf }\end{array}$ & $\begin{array}{l}\text { Perivascular } \\
\text { score }\end{array}$ & $\begin{array}{c}\text { Total cell } \\
\text { number/hpf }\end{array}$ & $\begin{array}{l}\text { Perivascular } \\
\text { score }\end{array}$ \\
\hline $\begin{array}{l}\text { MRL } \\
10 \text { weeks }\end{array}$ & $\begin{array}{c}B n^{+/+} \\
{B g n n^{+/+}}^{p L I V E} \\
B g n^{+/+} \mathrm{h} B G N\end{array}$ & $\begin{array}{l}4.2 \pm 1.3 \\
4.5 \pm 1.0 \\
8.1 \pm 1.4^{A}\end{array}$ & $\begin{aligned} 0 & \pm 0 \\
0 & \pm 0 \\
0.12 & \pm 0.04 \mathrm{~A}\end{aligned}$ & $\begin{array}{l}3.2 \pm 1.2 \\
3.0 \pm 1.3 \\
6.5 \pm 1.4^{\mathrm{A}}\end{array}$ & $\begin{aligned} 0 & \pm 0 \\
0 & \pm 0 \\
0.06 & \pm 0.03^{\mathrm{A}}\end{aligned}$ & $\begin{array}{l}0.21 \pm 0.12 \\
0.24 \pm 0.08 \\
0.36 \pm 0.20\end{array}$ & $\begin{array}{c}0 \pm 0 \\
0 \pm 0 \\
0.04 \pm 0.01^{\mathrm{A}}\end{array}$ \\
\hline $\begin{array}{l}\text { MRL/Ipr } \\
10 \text { weeks }\end{array}$ & $\begin{array}{c}B g n^{+/+} \\
B g^{+/+} \mathrm{pLIVE} \\
B g n^{-/} \\
B g n^{+/+} \mathrm{h} B G N\end{array}$ & $\begin{aligned} 18 & \pm 4.4 \\
18 & \pm 4.2 \\
8.3 & \pm 1.5^{\mathrm{B}} \\
35 & \pm 6.9^{\mathrm{C}}\end{aligned}$ & $\begin{aligned} 0.92 & \pm 0.21 \\
0.87 & \pm 0.18 \\
0.08 & \pm 0.02^{B} \\
1.7 & \pm 0.36^{C}\end{aligned}$ & $\begin{array}{l}6.0 \pm 1.0 \\
5.9 \pm 1.1 \\
3.4 \pm 0.80^{\mathrm{B}} \\
14 \pm 3.8^{\mathrm{C}}\end{array}$ & $\begin{array}{l}0.19 \pm 0.10 \\
0.21 \pm 0.11 \\
0.04 \pm 0.02^{B} \\
0.61 \pm 0.16^{C}\end{array}$ & $\begin{array}{l}7.8 \pm 1.5 \\
7.9 \pm 1.2 \\
3.8 \pm 0.41^{B} \\
13 \pm 2.1^{C}\end{array}$ & $\begin{array}{r}0.54 \pm 0.16 \\
0.53 \pm 0.12 \\
0.03 \pm 0.01^{B} \\
1.1 \pm 0.22^{\mathrm{C}}\end{array}$ \\
\hline 16 weeks & $\begin{array}{l}\mathrm{Bgn}^{+/+} \\
\mathrm{Bgn}^{-/}\end{array}$ & $\begin{array}{l}55 \pm 9.6 \\
29 \pm 4.9 \mathrm{~B}\end{array}$ & $\begin{array}{l}2.4 \pm 0.21 \\
1.4 \pm 0.23^{B}\end{array}$ & $\begin{array}{c}16 \pm 2.1 \\
9.2 \pm 1.8^{B}\end{array}$ & $\begin{array}{l}0.88 \pm 0.10 \\
0.45 \pm 0.14^{B}\end{array}$ & $\begin{array}{l}19 \pm 3.1 \\
10 \pm 2.0^{\mathrm{B}}\end{array}$ & $\begin{array}{c}1.5 \pm 0.22 \\
0.78 \pm 0.14^{B}\end{array}$ \\
\hline 24 weeks & $\begin{array}{l}\mathrm{Bgn}^{+/+} \\
\mathrm{Bgn}^{-/-}\end{array}$ & $\begin{array}{l}73 \pm 19 \\
38 \pm 8.3^{B}\end{array}$ & $\begin{array}{l}3.0 \pm 0.32 \\
1.6 \pm 0.65^{B}\end{array}$ & $\begin{array}{l}21 \pm 4.3 \\
12 \pm 2.8^{B}\end{array}$ & $\begin{array}{c}1.8 \pm 0.12 \\
0.71 \pm 0.09 \mathrm{~B}\end{array}$ & $\begin{array}{l}29 \pm 4.1 \\
18 \pm 3.7^{B}\end{array}$ & $\begin{array}{l}2.5 \pm 0.25 \\
1.5 \pm 0.39 \mathrm{~B}\end{array}$ \\
\hline
\end{tabular}

pLIVE, mice transiently transfected for 7 days with the pLIVE vector. hBGN, mice transiently transfected for 7 days with human biglycan inserted into the pLIVE vector. Cells were quantified as described in Methods section (hpf, $\times 400$ ). Perivascular regions were excluded from the total cell count. Values are given as mean $\pm \mathrm{SD}$ for $n=6$ per group. ${ }^{A} P<0.05 \mathrm{hBGN}$ MRL versus age-matched $B g n^{+/+} \mathrm{MRL}$ mice. ${ }^{B} P<0.05 B g n^{-/-} \mathrm{MRL} / / \mathrm{p} r$ versus age-matched $\mathrm{Bgn}^{+/+} \mathrm{MRL} / \mathrm{lp}$ r mice. ${ }^{\mathrm{C}} \mathrm{P}<0.05 \mathrm{hBGN} \mathrm{MRL} / \mathrm{lp} r$ versus age-matched $B g n^{+/+} \mathrm{MRL} / / \mathrm{pr}$ mice.

of mononuclear cells (Tables 4 and 6) in MRL control kidneys without symptoms of LN. Therefore, the hBGN pLIVE overexpression induced in respective knockout mice represents a good model to determine whether biglycan does in fact act via TLR2/4 in vivo as an endogenous trigger of inflammation. To prove this hypoth-

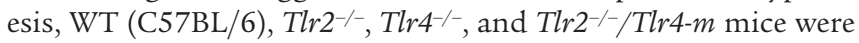
injected intravenously with $\mathrm{h} B G N$ pLIVE or with an empty pLIVE vector or vehicle alone to generate respective control mice. The efficiency of transfection was assessed by verifying $\mathrm{h} B G N$ expression in the liver (RT-PCR amplified cDNA digested with SacI) and circulating biglycan in the plasma at day 7 following transfection in each individual mouse. Animals with a 6- to 8-fold elevation of circulating biglycan were considered for the experiments. There were no genotype-specific differences in hepatic expression of $\mathrm{h} B G N$ and plasma levels of biglycan.

In agreement with the results obtained from MRL mice, 7 days of transfection with $\mathrm{h} B G N$ resulted in marked elevation of plasma (Supplemental Table 3) and renal levels of CXCL13 (Figure 10A), TNF- $\alpha$ (Figure 10B), IL-1 $\beta$ (Figure 10C), RANTES (Figure 10D), MCP-1 (Figure 10E), and MIP-1 $\alpha$ (Figure 10F) in hBGN WT mice. Importantly, enhanced levels of these proinflammatory factors, triggered by the overexpression of soluble biglycan, were partially reduced in hBGN $\operatorname{Tlr}^{-2^{--}}$, markedly decreased in hBGN $\mathrm{Tlr}^{-4^{--}}$, and completely abrogated in the kidney and plasma from $\mathrm{h} B G N$ Tlr2-/- Tlr4- $m$ mice (Figure 10, A-F, for renal and Supplemental Table 3 for plasma levels). In consequence, the number of infiltrating mononuclear cells was elevated in kidneys from $\mathrm{h} B G N$ WT mice, reduced in hBGN Tlr2-/- and in hBGN Tlr4-/- kidneys, and completely abolished in kidneys from $\mathrm{h} B G N \mathrm{Tlr} 2^{-/-} / \mathrm{Tl} 4-\mathrm{m}$ mice (Table 7). Control mice injected with an empty pLIVE vector or vehicle revealed no differences between genotypes on plasma (Supplemental Table 3) or renal levels of CXCL13 (Figure 10A), TNF- $\alpha$ (Figure 10B), IL-1 $\beta$ (Figure 10C), RANTES (Figure 10D),
MCP-1 (Figure 10E), and MIP-1 $\alpha$ (Figure 10F) and in the number of infiltrating mononuclear cells in the kidney (Table 7). These findings prove that soluble biglycan triggers an inflammatory response in vivo via TLR2 and TLR4.

Biglycan in plasma and renal biopsies from patients with diabetic nephropathy or acute renal allograft rejection in association with circulating proinflammatory cytokines and chemokines. The above-mentioned observations raised the question of whether renal diseases other than LN might involve biglycan as an endogenous mediator of inflammation. To investigate this possibility, levels of circulating biglycan, proinflammatory cytokines (TNF- $\alpha$ and IL-1 $\beta$ ), and chemokines (MCP-1, RANTES, and CXCL13), which we found to be triggered by biglycan (Figures 6-9, Table 5, and Supplemental Table 3), were analyzed in plasma obtained from patients with manifest diabetic nephropathy (DN) or acute renal allograft rejection (AR). The clinical characteristics of these patients are provided in Supplemental Table 4. Slightly, but not significantly, enhanced levels of circulating biglycan (Figure 11, A and B) in association with increased concentration of RANTES (Figure $11 \mathrm{~F}$ ) were detected in plasma samples from patients with DN $(n=7)$. In contrast, AR patients had elevated levels of circulating biglycan $(3.4 \pm 1.2$-fold control, $n=6, P<0.05)$, but not as high as those in patients with LN (Figure $1, \mathrm{~A}$ and $\mathrm{B}$ ). In accordance, TNF- $\alpha$ (Figure 11C), IL-1 $\beta$ (Figure 11D), MCP-1 (Figure 11E), RANTES (Figure 11F), and CXCL13 (Figure 11G) plasma levels were enhanced in patients with AR. Immunostaining for biglycan in renal biopsies from the same patients with DN (Figure 11, K and L) or AR (Figure 11, N-P) showed enhanced deposition of biglycan in glomeruli and tubulointerstitium (Figure 11L for DN and Figure 11, $\mathrm{O}$ and $\mathrm{P}$, for $\mathrm{AR}$ ) from diabetic (Figure $11 \mathrm{~K}$ ) and AR (Figure $11 \mathrm{~N}$ ) patients in comparison with healthy controls (Figure 11, H and I). Biglycan staining was more intense in the biopsies from patients with AR (Figure 11O) as compared with 
A

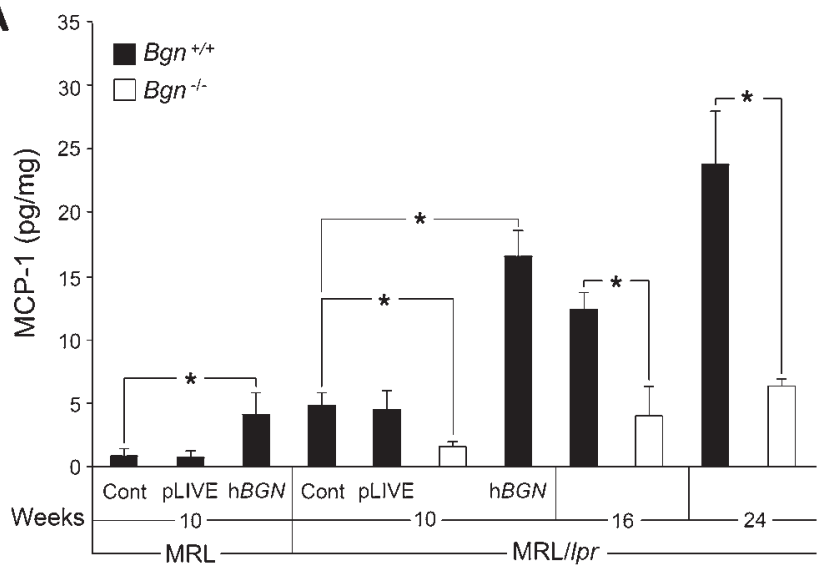

C

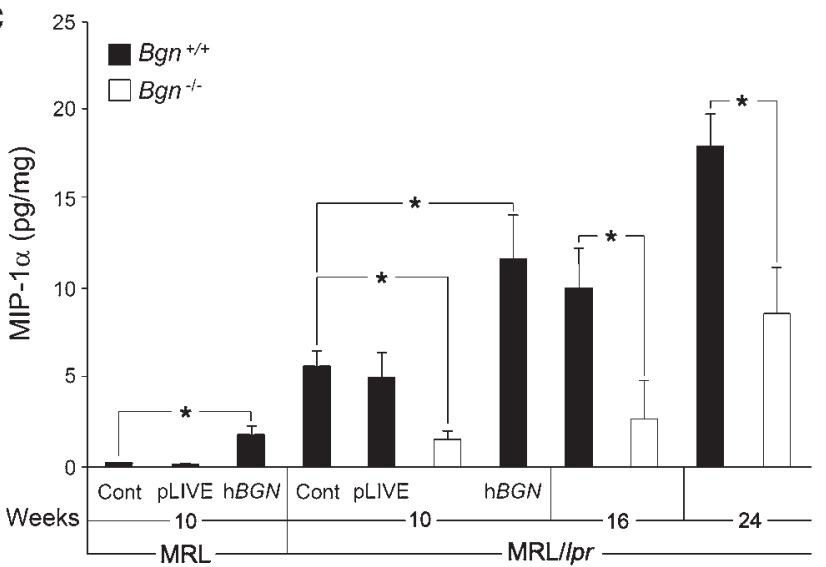

B

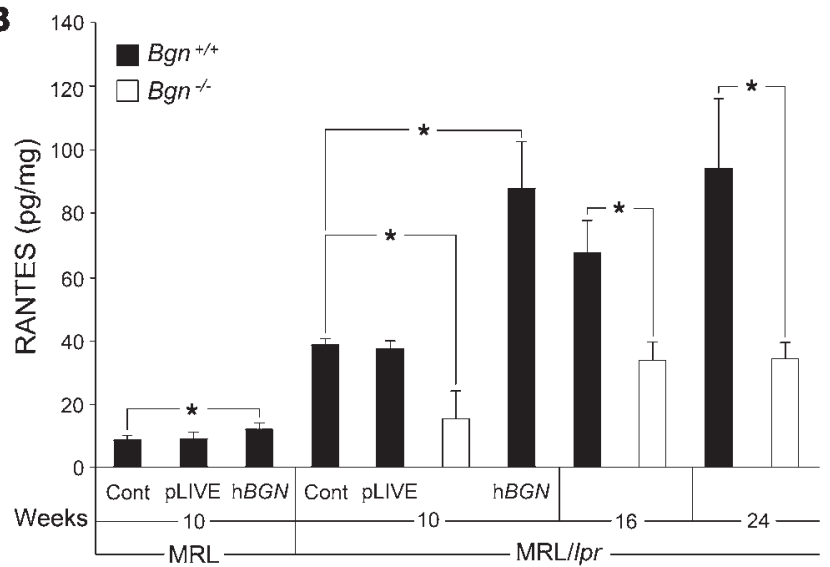

D

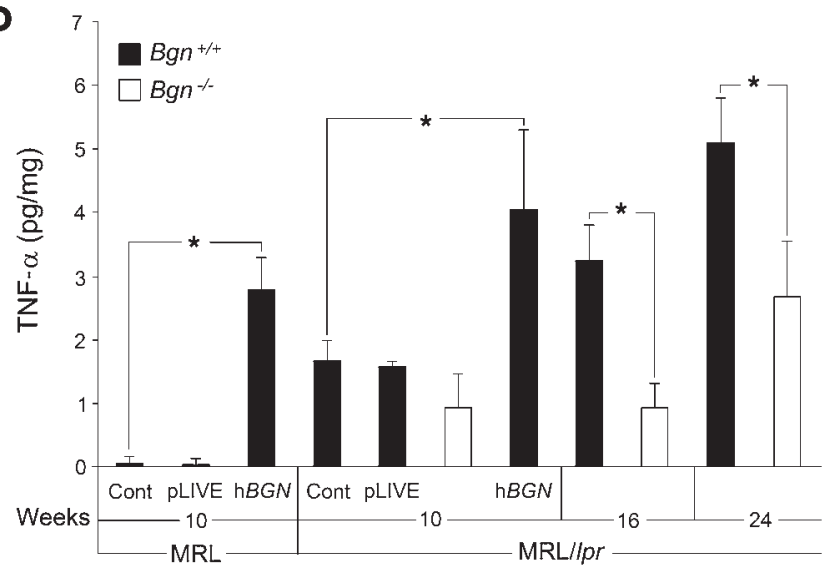

Figure 6

Effects of biglycan deficiency and overexpression on renal levels of MCP-1, RANTES, MIP-1 $\alpha$, and TNF- $\alpha$. Ten-week-old Bgn+/+MRL, $\mathrm{Bgn}^{+/+} \mathrm{MRL} / / \mathrm{pr}, \mathrm{Bgn}{ }^{-/} \mathrm{MRL} / / \mathrm{pr}$, and $\mathrm{hBGN}$ mice and their respective controls as well as 16- and 24-week-old Bgn ${ }^{-/-\mathrm{MRL} / / p r}$ and $\mathrm{Bgn}^{+/+} \mathrm{MRL} / \mathrm{lpr}$ mice were analyzed for MCP1 (A), RANTES (B), MIP-1 $\alpha$ (C), and TNF- $\alpha$ (D) protein in total kidney homogenates using ELISA. Chemokine and cytokine levels were normalized to total protein. Renal levels of MCP1, RANTES, MIP-1 $\alpha$, and TNF- $\alpha$ were reduced in biglycan-deficient $\mathrm{MRL} / / p r$ versus $\mathrm{Bgn}^{+/+} \mathrm{MRL} / / p r$ mice at all time points examined. In contrast, biglycan overexpression caused a significant increase in the renal content of these chemo- and cytokines as compared with pLIVE- or only solvent-injected control animals. Notably, MCP-1, RANTES, MIP-1 $\alpha$, and TNF- $\alpha$ were enhanced in the kidney from biglycan-overexpressing MRL mice. Data are given as mean \pm SD. Asterisks indicate statistical significance; $n=6 .{ }^{*} P<0.05$.

DN (Figure 11L). Biglycan was preferentially located in the peritubular space, around and in some of the infiltrating mononuclear cells both in DN (Figure 11L) and AR (Figure 11, $\mathrm{O}$ and P).

\section{Discussion}

In this report, we show for what we believe is the first time that CXCL13 can be regulated by the proteoglycan biglycan, which acts as a host-derived ligand for TLR2/4 in LN. The chemokine CXCL13 is a valuable marker of disease activity and renal involvement in SLE patients and in the NZB/W-F1 mouse model of $\operatorname{SLE}(16,25)$. In agreement with these observations, we found enhanced plasma levels of CXCL13 in patients suffering from type IV LN as well as in lupus-prone MRL/lpr and NZB/W-F1 mice. Interestingly, renal Cxcl13 mRNA and protein were overexpressed starting at the onset of disease, even prior to the appearance of renal manifestations. Expression of CXCL13 in the kidneys of MRL/lpr mice progressively increased during the course of LN. Furthermore, elevated levels of CXCL13 correlated with enhanced numbers of B cells in the kidney, glomerular and tubulointerstitial damage, albuminuria, and loss of renal function. Thus, our observations further support the notion that CXCL13, aside from its involvement in the recruitment of CXCR5-expressing B lymphocytes to secondary lymphoid organs, also attracts B cells to chronically inflamed nonlymphoid organs (e.g., kidney). This in turn leads to the development of tertiary lymphoid tissue promoting acceleration of disease (10, 31-33). The mechanisms regulating CXCL13 expression in nonlymphoid organs, however, have not yet been elucidated.

We show in this report that soluble biglycan acts as an endogenous trigger for renal CXCL13 expression in LN. The striking correlation between biglycan (both circulating and renal) and CXCL13 levels in LN patients and in MRL/lpr or NZB/W-F1 mice provided the first clue for the involvement of biglycan in the regulation of CXCL13. Biglycan plasma levels of MRL/lpr mice were already elevated at the onset of LN. It is therefore unlikely that the continuous increase in circulating biglycan 


\section{Table 5}

Plasma levels of selected chemokines and cytokines in $\mathrm{Bgn}^{+/+} \mathrm{MRL}$ and MRL/lpr mice lacking or overexpressing biglycan

\begin{tabular}{|c|c|c|c|c|c|c|}
\hline \multicolumn{2}{|c|}{ Genotype } & MCP-1 (pg/ml) & RANTES (pg/ml) & $\mathrm{MIP}-1 \alpha(\mathrm{pg} / \mathrm{ml})$ & TNF- $\alpha(\mathrm{pg} / \mathrm{ml})$ & IL-1 $\beta(p g / m I)$ \\
\hline \multicolumn{7}{|l|}{ MRL } \\
\hline \multirow[t]{3}{*}{10 weeks } & $B g n^{+/+}$ & $20 \pm 5.8$ & $92 \pm 12$ & $3.2 \pm 1.0$ & $2.1 \pm 0.31$ & $7.2 \pm 2.6$ \\
\hline & $\mathrm{Bgn}^{+/+} \mathrm{pLIVE}$ & $22 \pm 3.9$ & $89 \pm 18$ & $3.5 \pm 0.92$ & $1.9 \pm 0.43$ & $6.6 \pm 2.4$ \\
\hline & $\mathrm{Bgn}^{+/+} \mathrm{h} B G N$ & $47 \pm 12^{A}$ & $136 \pm 23^{A}$ & $6.3 \pm 1.2^{\mathrm{A}}$ & $6.1 \pm 2.5^{\mathrm{A}}$ & $15 \pm 3.9^{A}$ \\
\hline \multicolumn{7}{|l|}{$\mathrm{MRL} / / p r$} \\
\hline \multirow[t]{4}{*}{10 weeks } & $B g n^{+/+}$ & $66 \pm 22$ & $130 \pm 10$ & $8.9 \pm 1.6$ & $14 \pm 1.5$ & $57 \pm 15$ \\
\hline & $\mathrm{Bgn}^{+/+} \mathrm{pLIVE}$ & $65 \pm 18$ & $127 \pm 15$ & $9.0 \pm 1.0$ & $14 \pm 3.0$ & $59 \pm 13$ \\
\hline & $\mathrm{Bgn}^{-/-}$ & $24 \pm 8.0^{B}$ & $75 \pm 17^{B}$ & $3.7 \pm 0.80^{B}$ & $4.7 \pm 2.1^{B}$ & $24 \pm 6.9^{B}$ \\
\hline & $B g n^{+/+} \mathrm{h} B G N$ & $137 \pm 44^{C}$ & $256 \pm 68^{C}$ & $20 \pm 4.9 c$ & $41 \pm 2.9 c$ & $114 \pm 29 c$ \\
\hline \multirow[t]{2}{*}{16 weeks } & $\mathrm{Bgn}^{+/+}$ & $152 \pm 32$ & $243 \pm 41$ & $72 \pm 10$ & $49 \pm 3.6$ & $111 \pm 21$ \\
\hline & $\mathrm{Bgn}^{-/-}$ & $68 \pm 2.8^{B}$ & $153 \pm 11^{B}$ & $32 \pm 8.6^{B}$ & $33 \pm 2.6^{B}$ & $42 \pm 14^{B}$ \\
\hline \multirow[t]{2}{*}{24 weeks } & $\mathrm{Bgn}^{+/+}$ & $192 \pm 21$ & $545 \pm 111$ & $105 \pm 27$ & $77 \pm 4.5$ & $134 \pm 39$ \\
\hline & $\mathrm{Bgn}^{-/-}$ & $105 \pm 12^{B}$ & $337 \pm 22^{B}$ & $50 \pm 5.7^{B}$ & $42 \pm 4.4^{B}$ & $55 \pm 12^{\mathrm{B}}$ \\
\hline
\end{tabular}

pLIVE, mice transiently transfected for 7 days with the pLIVE vector. hBGN, mice transiently transfected for 7 days with human biglycan inserted into the pLIVE vector. Values are given as mean $\pm \mathrm{SD}$ for $n=6$ per group; ${ }^{A} P<0.05 \mathrm{hBGN} \mathrm{MRL}$ versus age-matched $B g n^{+/+} \mathrm{MRL}$ mice. ${ }^{B} P<0.05 B g n^{-/} \mathrm{MRL} / / p r$ versus age-matched $B g n^{+/+} \mathrm{MRL} / / p r$ mice. ${ }^{C} P<0.05 \mathrm{hBGN}$ MRL/lpr versus age-matched $B g n^{+/+} \mathrm{MRL} / / p r$ mice.

levels might have been caused by a decline in the glomerular filtration rate. As not only the increase of biglycan, CXCL13, and $B$ cell count in LN patient kidneys, but also the renal expression pattern of biglycan were closely reflected in 2 experimental murine models of LN, we feel confident that our use of the MRL/ $l p r$ mouse was the appropriate choice for analyzing biglycan/ CXCL13/B cell interactions in LN.

The continuous rise of the biglycan plasma concentrations during the course of LN was most likely due to de novo synthesis of this proteoglycan in target organs, as shown here for the kidney. It has been unequivocally demonstrated that TGF- $\beta$, which is overexpressed in murine and human LN $(34,35)$, acts as a crucial trigger of biglycan synthesis in various renal cell types (36-38). Additionally, macrophages upon stimulation by proinflammatory cytokines, such as IL- 6 and IL-1 $\beta$, start to express biglycan mRNA and secrete the proteoglycan during inflammation, thereby boosting the inflammatory response in an autocrine and paracrine manner $(2,5)$. It is therefore tempting to speculate that the number of activated macrophages in inflamed organs has critical effects on the levels of de novo synthesized biglycan in LN. Some of the de novo synthesized biglycan is sequestered in situ by the ECM and gives rise to the here reported renal accumulation of this proteoglycan. Sequestered biglycan acts as a structural matrix component with no apparent immunological function (2). It is conceivable that some biglycan spills over into the circulatory system when its synthesis exceeds the capacity of the ECM to sequester this proteoglycan. Moreover, proteolytic enzymes released from infiltrating or resident cells are able to liberate sequestered biglycan from the $\operatorname{ECM}(39,40)$, thereby generating a rapid response to tissue damage without a need for de novo synthesis of this proinflammatory molecule. Thus, it is possible that matrix-derived biglycan could also make a contribution to the circulating pool of this proteoglycan.

Previously, we have shown that only the soluble but not the ECM-bound biglycan is capable of engaging cell surface receptors, thereby triggering an inflammatory response reaction both under pathogen-dependent and -independent conditions (1-3, $41,42)$. Therefore, we generated transiently transgenic MRL/lpr mice (and the respective controls) by overexpressing soluble biglycan in the liver under the control of an albumin promoter for 7 days at the onset of LN. In this model, biglycan mRNA is exclusively overexpressed in the liver and secreted into the circulation. This leads to a marked enhancement of biglycan in the circulation and in several organs including the kidney, mimicking the constellation observed in advanced stages of LN. In fact, in vivo overexpression of soluble biglycan caused a marked increase in renal Cxcl13 mRNA and protein expression as well as circulating CXCL13 in MRL/lpr mice. This resulted in elevated numbers of B cells expressing the CXCR5 receptor in the kidney with enhanced organ damage and albuminuria. It is important to note that enhanced levels of soluble biglycan not only accelerated LN, but also triggered the expression of CXCL13 with subsequent infiltration of B cells in the healthy kidney. This observation suggests that biglycan initiates CXCL13 expression and B cell influx into the kidney not only in LN but probably in other B cell-dependent disease entities as well.

This potential relationship between biglycan and CXCL13 in human AR (32) and in DN (43), 2 inflammatory kidney diseases either with or without B cell involvement, was determined. Patients with AR showed elevated levels of circulating and renal biglycan in association with enhanced plasma CXCL13 levels. Similar findings in terms of plasma CXCL13 levels have been reported for rejecting renal allografts (32). In contrast, only the renal biglycan content was increased in $\mathrm{DN}$, a chronic inflammatory process associated with significantly fewer infiltrating cells as compared with AR. Neither circulating CXCL13 nor biglycan was markedly elevated. Enhanced renal accumulation of biglycan was probably due to TGF- $\beta$, which is markedly overexpressed in DN $(44,45)$, and presumably represented the ECM-bound proteoglycan. Thus, it appears that activated infiltrating cells, in addition to resident renal cells, stimulate the synthesis of biglycan to such an extent that the binding capacity of the ECM becomes saturated, and subsequently soluble biglycan spills over into the circulation. 
A

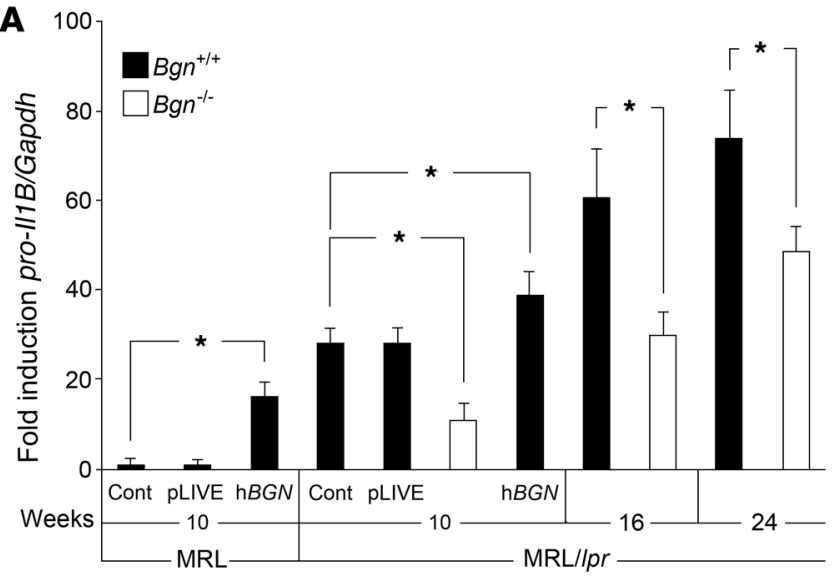

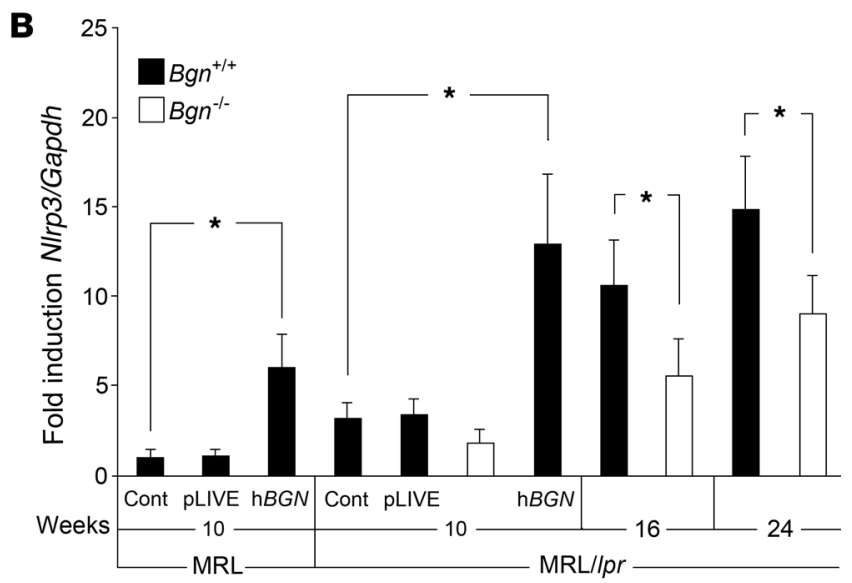

D

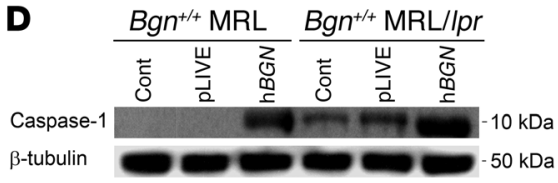

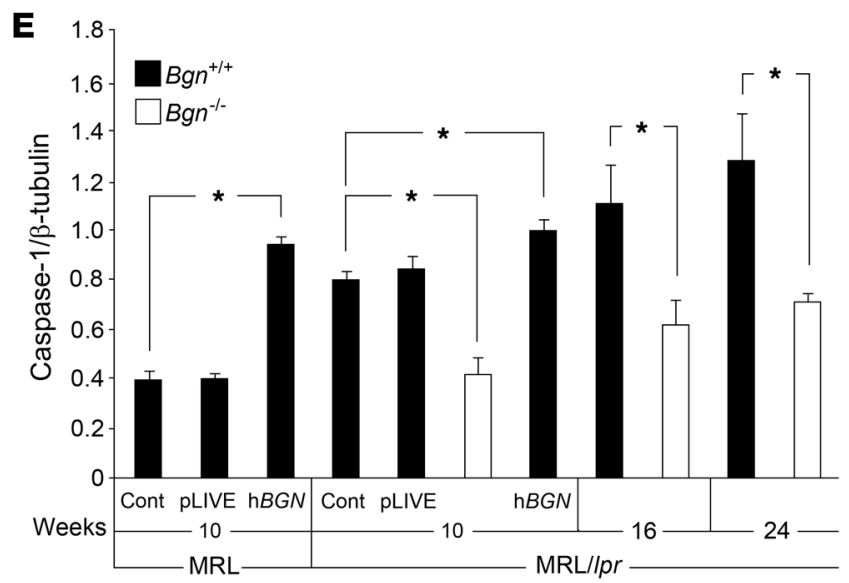

$\mathbf{F}$

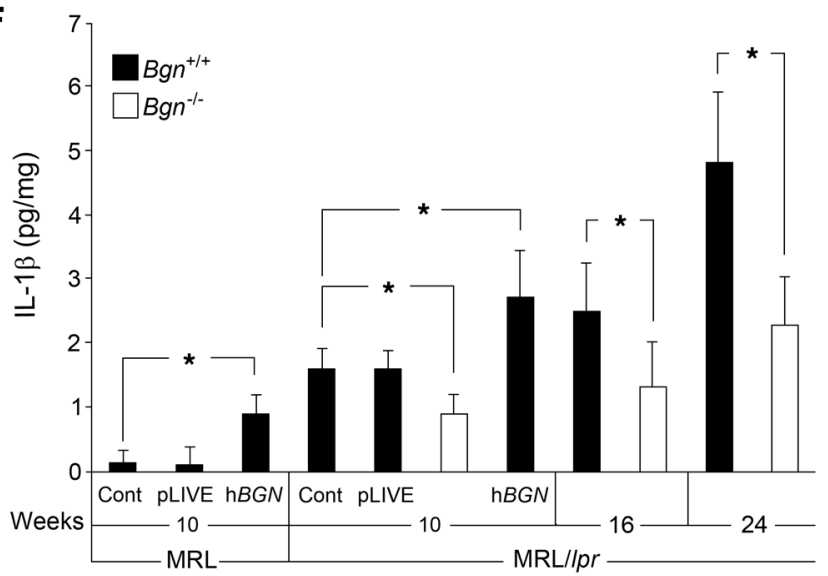

Figure 7

Influence of biglycan on the expression of pro-I/1B and N/rp3 and levels of active caspase-1 and mature IL-1 $\beta$ in kidneys from MRL/Ipr and MRL mice. Ten-week-old Bgn+/+MRL, Bgn+/+MRL/lpr, Bgn-/-MRL/lpr, hBGN mice and their respective controls, as well as 16- and 24-week-old $\mathrm{Bgn}^{-/-\mathrm{MRL} / / p r}$ and $\mathrm{Bgn}{ }^{+/+\mathrm{MRL} / / p r}$ mice were analyzed for pro-I/1B and NIrp3 mRNA expression, active caspase-1, and content of mature IL-1 $\beta$ in total kidney homogenates. (A and B) TaqMan analysis for the renal expression of pro-I/1B (A) and NIrp3 (B) shown as the average-fold induction relative to controls (Bgn+/+MRL) (normalized to Gapdh). (C and D) Western blots for active caspase-1 in kidneys from (C) 10-, 16-, and

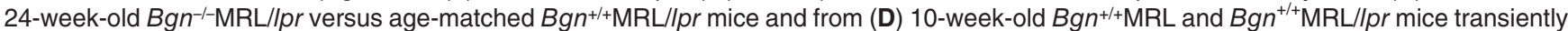
transfected with hBGN, empty-vector- (pLIVE) and control solvent-injected mice normalized to $\beta$-tubulin and (E) quantified for 3 independent experiments. As there were no genotypic or age-dependent (10-24 weeks) differences in renal expression of pro-I/1B (A) and NIrp3 (B), levels of active caspase-1 (C-E), and mature IL-1 $\beta(\mathbf{F})$, only results from 10- (A, B, and D-F) and 24-week-old (C) Bgn ${ }^{+/+}$MRL mice were used as controls. Data are given as mean $\pm \mathrm{SD}$. Asterisks indicate statistical significance; $n=6(\mathbf{A}, \mathbf{B}$, and $\mathbf{F})$ and $n=3(\mathbf{E}) .{ }^{*} P<0.05$.

To gain some insight into the mechanism of biglycan-mediated expression of CXCL13, in vitro experiments were performed stimulating primary spleen-derived dendritic cells and resident peritoneal macrophages with biglycan. Several studies postulated that antigen-presenting cells express CXCL13 and colocalize with areas of $B$ cell infiltration in $\operatorname{LN}(25,46,47)$. However, due to difficulties in defining specific cellular markers and anti-CXCL13 antibodies, in particular against mouse antigens (our unpublished observations), other cellular sources of renal CXCL13 could not be excluded $(10,33)$. In dendritic cells and macrophages, we found good evidence for biglycan-induced expression of CXCL13, strongly supporting our in vivo data. Contaminations are unlikely to have caused these effects, as contaminatory products have been rigorously excluded by several assays (2).

Furthermore, we identified TLR 2 and TLR4 as receptors involved in the biglycan-dependent CXCL13 induction pathway in both cell types. Importantly, by overexpressing soluble biglycan in TLR2-, TLR4-, or TLR2/4-deficient mice, we provided 


\section{Table 6}

Quantification of $B$ and $B 1$ cells in $B g n^{+/}+M R L$ and MRL/lpr mice lacking or overexpressing biglycan and their respective controls (FACS analysis)

\begin{tabular}{|c|c|c|c|c|}
\hline \multicolumn{2}{|c|}{ Genotype } & \multirow{2}{*}{$\begin{array}{c}\text { B lymphocytes } \times 10^{4} / \text { kidney } \\
\text { (CD19+) } \\
\\
4.6 \pm 1.7 \\
5.4 \pm 1.8 \\
10 \pm 1.9 \mathrm{~A}\end{array}$} & \multirow{2}{*}{$\begin{array}{c}\text { B1 lymphocytes } \times 10^{4} / \text { kidney } \\
\text { (CD5+CD19+) } \\
\\
0.42 \pm 0.19 \\
0.52 \pm 0.24 \\
1.4 \pm 0.55^{\mathrm{A}}\end{array}$} & \multirow{2}{*}{$\begin{array}{l}\text { B1/B lymphocytes (\%) } \\
\\
\begin{array}{l}10 \pm 4.5 \\
11 \pm 7.7 \\
14 \pm 4.0\end{array}\end{array}$} \\
\hline $\begin{array}{l}\text { MRL } \\
10 \text { weeks }\end{array}$ & $\begin{array}{c}B g^{+/+} \\
B g^{+/+} \text {pLIVE } \\
B g n^{+/+} \mathrm{h} B G N\end{array}$ & & & \\
\hline $\begin{array}{l}\text { MRL/lpr } \\
10 \text { weeks }\end{array}$ & $\begin{array}{c}B g n^{+/+} \\
{B g n n^{+/+} \mathrm{pLIVE}} \mathrm{Bgn}^{-/-} \\
\mathrm{Bgn}^{+/+} \mathrm{h} B G N\end{array}$ & $\begin{array}{c}13 \pm 2.6 \\
14 \pm 1.9 \\
5.8 \pm 2.8^{B} \\
23 \pm 3.5^{C}\end{array}$ & $\begin{array}{r}2.0 \pm 0.71 \\
2.2 \pm 0.84 \\
0.58 \pm 0.32^{B} \\
5.2 \pm 0.84^{C}\end{array}$ & $\begin{array}{l}16 \pm 6.1 \\
16 \pm 6.4 \\
10 \pm 3.1 \\
22 \pm 3.2^{c}\end{array}$ \\
\hline 16 weeks & $\begin{array}{l}\mathrm{Bgn}^{+/+} \\
\mathrm{Bgn}^{-/}\end{array}$ & $\begin{array}{l}38 \pm 4.2 \\
12 \pm 1.9^{B}\end{array}$ & $\begin{array}{c}11 \pm 1.9 \\
2.0 \pm 0.71^{B}\end{array}$ & $\begin{array}{l}28 \pm 2.6 \\
17 \pm 5.1^{B}\end{array}$ \\
\hline 24 weeks & $\begin{array}{l}\mathrm{Bgn}^{+/+} \\
\mathrm{Bgn}^{-/}\end{array}$ & $\begin{array}{l}47 \pm 6.2 \\
20 \pm 2.3^{B}\end{array}$ & $\begin{array}{c}14 \pm 3.1 \\
4.2 \pm 1.3^{B}\end{array}$ & $\begin{array}{l}30 \pm 4.5 \\
21 \pm 7.3^{в}\end{array}$ \\
\hline
\end{tabular}

For isolation of mononuclear cells, 6 whole kidneys ( 3 mice) from each genotype and each age group were used. Five independent experiments were performed. B lymphocytes were isolated with CD19 MicroBeads and MACS Technology and then processed for FACS analysis. Values are given as mean $\pm \mathrm{SD}$ for $n=5$. ${ }^{A} P<0.05 \mathrm{hBGN}$ MRL versus age-matched $B g n^{+/+} \mathrm{MRL}$ mice. ${ }^{B} P<0.05 B g n^{-/-} \mathrm{MRL} / / p r$ versus age-matched $B g n^{+/+} \mathrm{MRL} / / p r$ mice. ${ }^{c} P<0.05 \mathrm{hBGN} \mathrm{MRL} / / p r$ versus age-matched $B g n^{+/+} \mathrm{MRL} / / p r$ mice.

direct in vivo evidence that biglycan triggers the expression of CXCL13 in the kidney in a TLR2/4-dependent manner. In contrast, the $\mathrm{P} 2 \mathrm{X} 7$ receptor, known to interact with biglycan (3), is not involved in the regulation of CXCL13 expression. Looking at downstream mediators of biglycan signaling (3), we could demonstrate that ROS are involved in CXCL13 regulation, while the inflammasome plays no regulatory role. Cooperation of multiple signaling cascades with crucial roles of the canonical and the noncanonical NF-кB pathways has been postulated to be involved in the regulation of CXCL13 (48). Up to now, several inducers of CXCL13, including retinoic acid, IL-10, LPS, and Borrelia garinii, have been described (49-51). Among those, Borrelia garinii stimulates CXCL13 production via TLR2 (50). Involvement of LPS and TNFR-associated factor 6 (TRAF6) suggested a potential role of TLR4 in the induction of CXCL13 $(49,52)$. However, to the best of our knowledge, this is the first report to show that an endogenous danger signal is capable of stimulating the major B cell chemoattractant via innate immunity receptors without involvement of PAMPs. Besides identifying the inducer of CXCL13 in LN, we have also shed some light on the role of TLRs in this condition. Previous observations identified host-derived nucleic acids as triggers of a systemic inflammatory response and autoantibody production in SLE via TLR3/7/9 $(18,20)$. Overexpression of TLR $2 / 4 / 7 / 9$ has been described in experimental and human $\operatorname{LN}(53,54)$. Moreover, upregulation of TLR4 signaling alone without an exogenous insult has been shown to be pathogenic in LN (53). Thus, the identification of biglycan as an endogenous trigger of TLR2- and TLR4-dependent induction of CXCL13 might explain, at least partially, the role of TLR2/4 in the evolution of LN.

In the current study, we also showed that biglycan-mediated upregulation of CXCL13 resulted in enhanced numbers of infiltrating B cells in the kidney and increased production of antibodies in LN. Interestingly, biglycan predominantly attracts the B1 cell subset of B lymphocytes. The role of B1 cells in the progress of $\mathrm{LN}$ in MRL/lpr mice has not been addressed yet. Our findings correspond well with earlier observations that aberrant expression of CXCL13 in target organs of aged NZB/W-F1 mice was associated with preferential chemotaxis of $\mathrm{B} 1$ cells to the kidney and with the development of LN (25). However, the initial trigger of CXCL13 has not been identified up to now. B1 lymphocytes are responsible for the T cell-independent production of antibodies involved in the early defense against PAMPs, before the adaptive immune response is initiated $(12-15,55,56)$. On the other hand, TLRs in response to PAMPs have been shown to regulate the migration of $\mathrm{B} 1$ cells from the peritoneal cavity to target organs by regulating the interplay among integrins, tetraspanins, and chemokine receptors (13). In the present report, we identified biglycan as a nonpathogen-derived ligand of TLR2/4 and trigger of CXCL13 expression in $\mathrm{LN}$, resulting in chemoattraction of $\mathrm{B}$ and $\mathrm{B} 1$ cells into the kidney. Thus, we suggest that biglycan is a previously unidentified and novel molecular link connecting the initial activation of TLRs, CXCL13 expression, and the enhanced numbers of renal B and B1 cells to the development of LN.

Previously, we were able to show that biglycan stimulates the expression of TNF- $\alpha$ and MIP-2 in macrophages via TLR2/4, resulting in enhanced infiltration of mononuclear cells in the lung and kidney under pathogen-dependent and -independent inflammatory conditions $(2,3)$. Furthermore, biglycan autonomously triggers the synthesis of pro-IL-1 $\beta$ and stimulates NLRP3-inflammasome/caspase-1-mediated maturation of IL-1 $\beta$ by clustering TLR2/4 with P2X7/P2X4 receptors (3). Here, we show that in LN, renal, and plasma levels of TNF- $\alpha$ as well as pro-IL-1 $\beta$, expression and inflammasome-mediated maturation of IL-1 $\beta$ critically depend on biglycan. Moreover, we could demonstrate that biglycan induced the expression of macrophage and T cell chemoattractants MCP-1, RANTES, and MIP- $1 \alpha$ in the plasma and kidneys of biglycan-overexpressing MRL/lpr and 
A

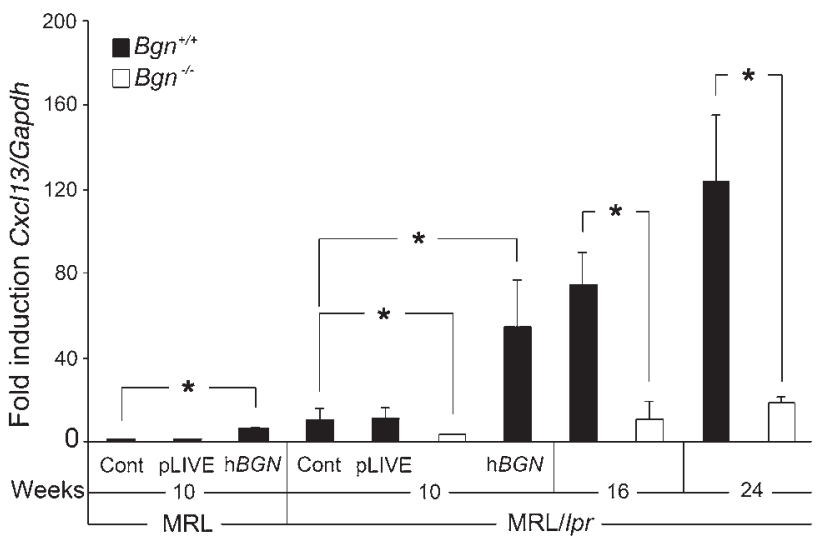

C

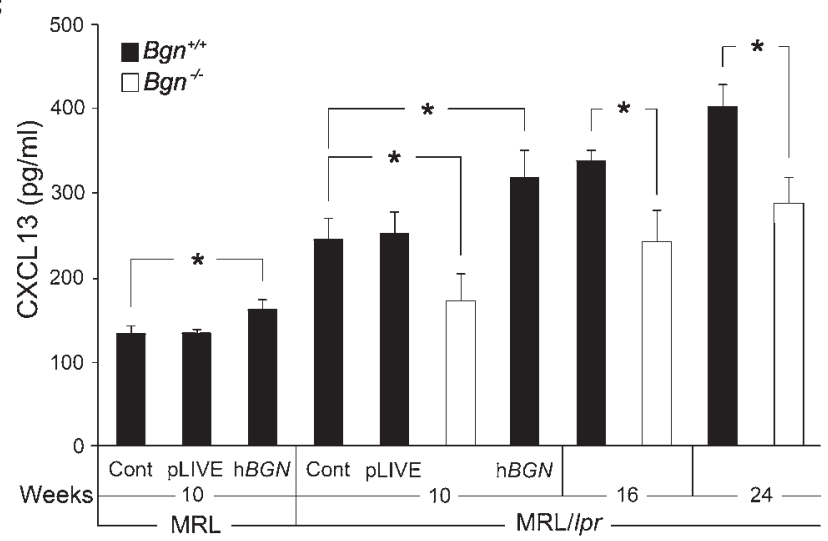

$\mathbf{E}$

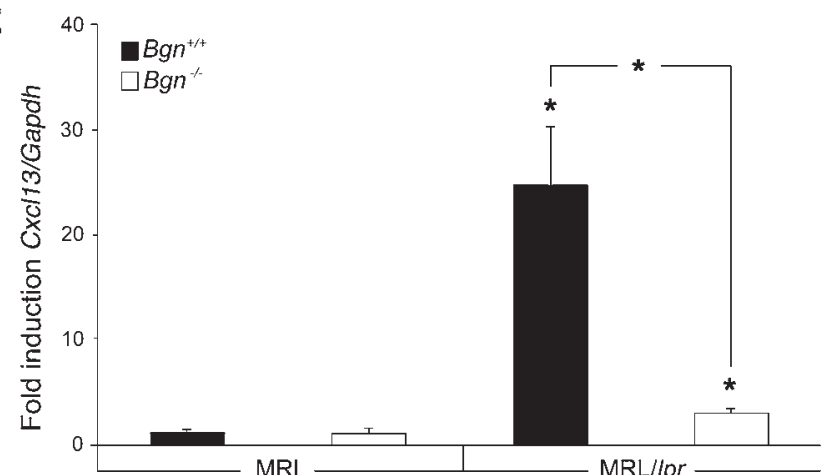

B

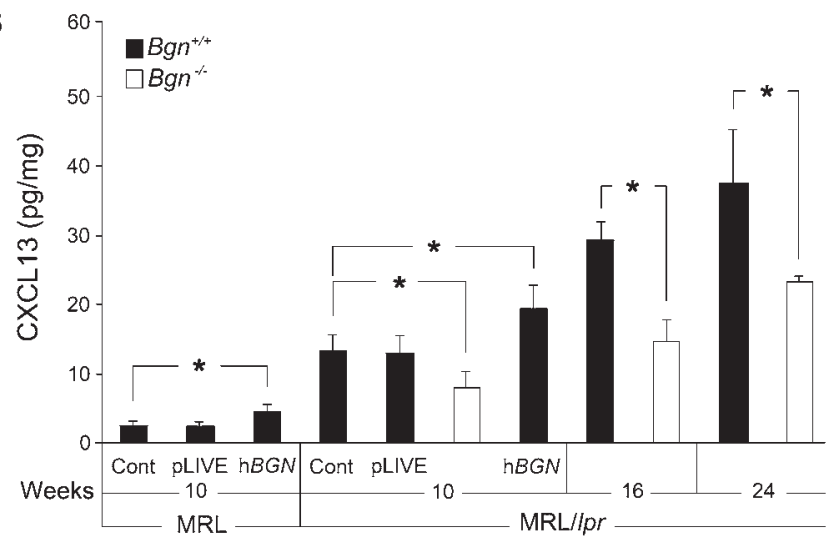

D

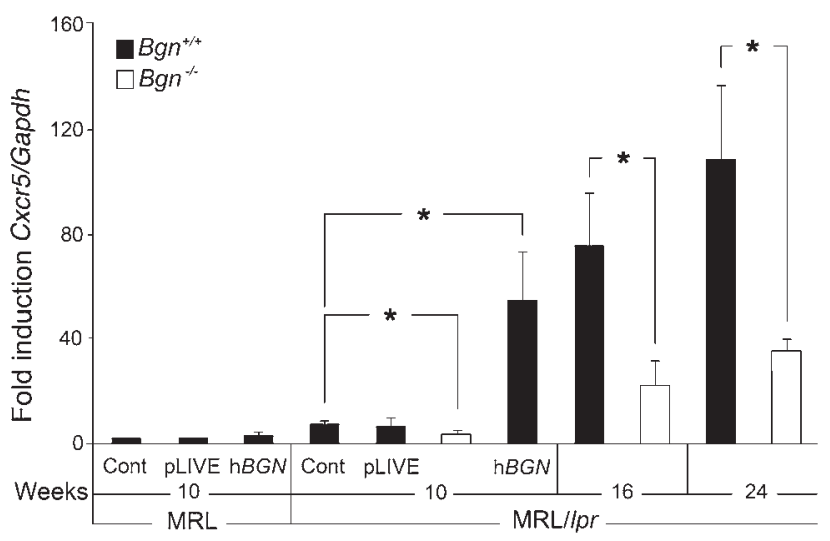

$\mathbf{F}$

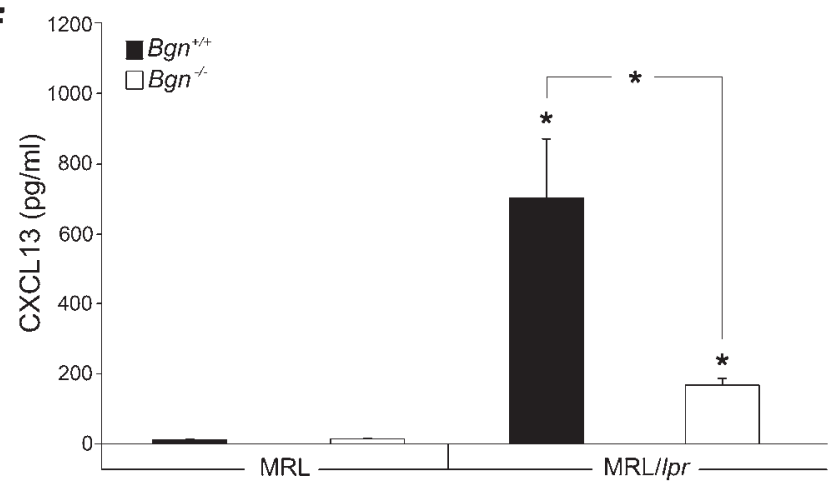

Figure 8

Effects of biglycan expression on the B cell chemoattractant CXCL13 in kidneys, plasma, and resident peritoneal macrophages from MRL/lpr mice. Ten-week-old $B g n^{+/+} \mathrm{MRL}, B g n^{+/+M R L / / p r}, B g n^{-/}$MRL//pr, hBGN, mice and their respective controls, as well as 16- and 24-week-old

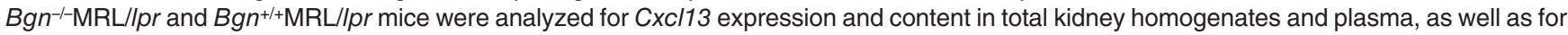
the renal expression of $C x c r 5$. (A and D) TaqMan analysis for the renal expression of $C x c / 13$ (A) and its receptor $C x c r 5$ (D) shown as the average fold induction relative to controls (Bgn $n^{++} \mathrm{MRL}$ ) (normalized to Gapdh) and (B and C) ELISA for CXCL13 from total kidney homogenates normalized to total protein (B) and from plasma (C). There were no differences in CXCL13 expression and levels between $B g n^{+/+} \mathrm{MRL}$ and $B g n^{-1-M R L}$ mice $(\mathbf{A}-\mathbf{D})$. (E and $\mathbf{F})$ TaqMan analysis $(\mathbf{E})$ and ELISA $(\mathbf{F})$ for CXCL13 in peritoneal macrophages $(E)$ or their culture supernatants $(\mathbf{F})$ from

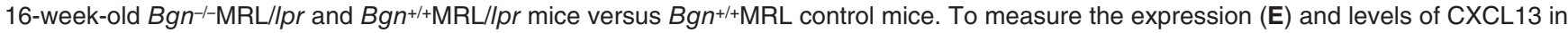
culture supernatants $(\mathbf{F})$, monocytes/macrophages were flushed from the peritoneal cavity and plated $\left(2 \times 10^{5}\right)$ under serum-free conditions for 12 hours and cells $(E)$ or culture supernatants $(\mathbf{F})$ were analyzed for CXCL13. TaqMan results $(E)$ are given as average fold induction relative to control, normalized to Gapdh. Asterisks indicate statistical significance; $n=6$. ${ }^{*} P<0.05$. Data are given as mean \pm SD.

healthy MRL mice, resulting in higher numbers of renal macrophages and T cells. The fact that soluble biglycan stimulated the expression of MCP-1, RANTES, and MIP- $1 \alpha$ and caused infiltration of macrophages and $T$ cells into the kidney not only in animals with LN but in healthy MRL mice as well underscores the pivotal role of this proteoglycan as an endogenous trigger of inflammation. Importantly, we provided direct in vivo evidence that biglycan triggers these cyto- and chemokines in a TLR2/4dependent manner. There are ample indications supporting the biological relevance of these chemokines in LN and various 
A

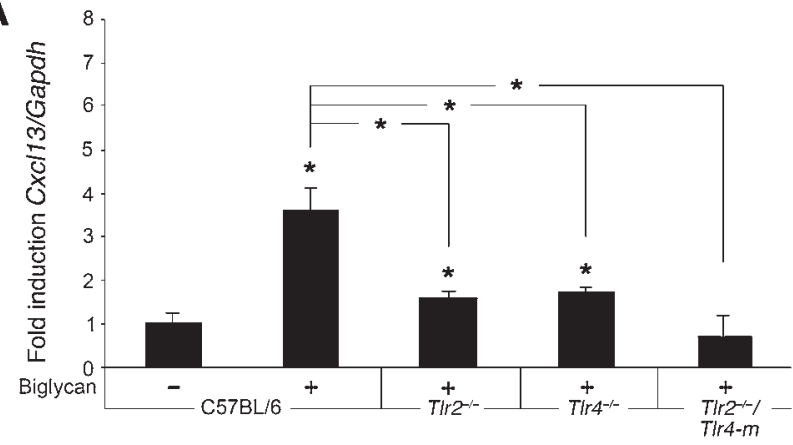

C

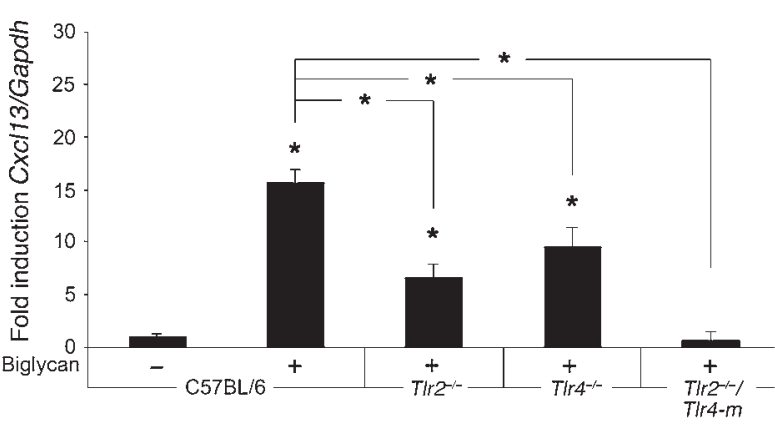

E

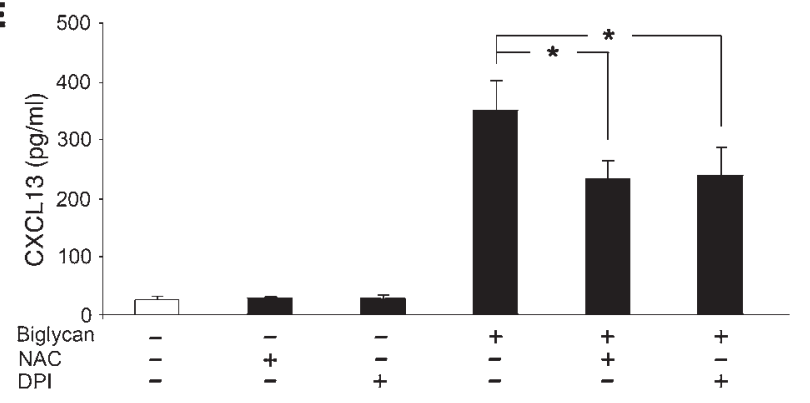

B

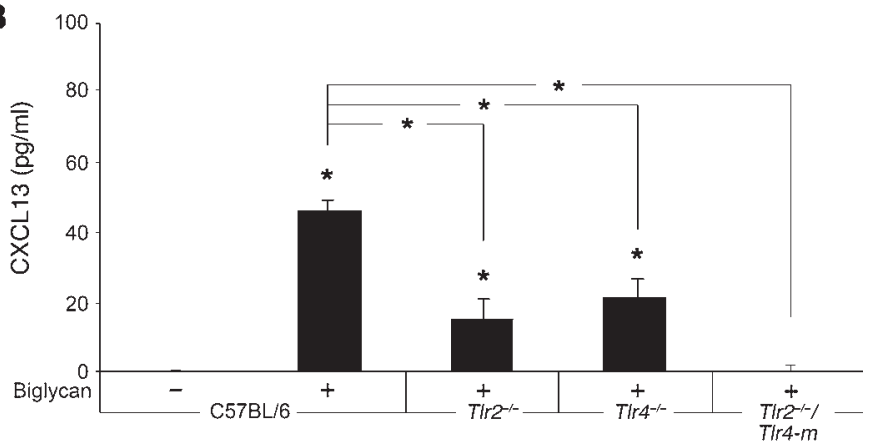

D
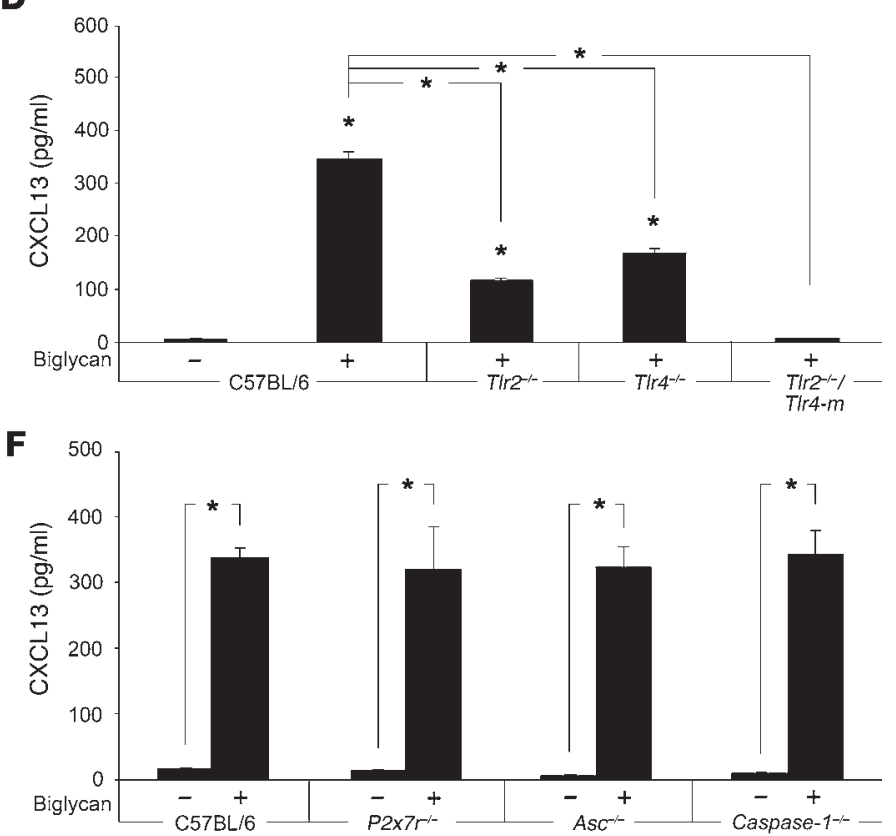

Figure 9

Biglycan triggers CXCL13 expression in spleen dendritic cells and residential macrophages in a TLR2/TLR4- and ROS-dependent manner. Cxc/13 mRNA (A and $\mathbf{C}$ ) and protein levels in cell culture supernatants (B, D-F) from spleen dendritic cells (A and $\mathbf{B})$ and macrophages (C-F)

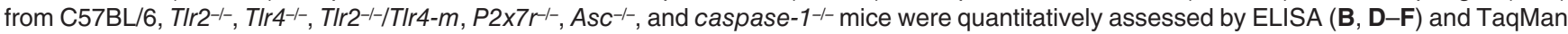
RT-PCR (A and C). Monocytes/macrophages and dendritic cells were isolated as described in Methods. TaqMan results (A and C) are given as average-fold induction over controls, normalized to Gapdh. Asterisks positioned over the respective bars indicate statistical significance for biglycan-stimulated cells compared with nonstimulated controls (A-D). (E and F) ELISA for CXCL13 in culture media from (E) C57BL/6 macrophages preincubated with NAC $(10 \mathrm{mM})$ or DPI $(0.5 \mathrm{mM})$ for 1 hour from $(\mathbf{F}) \mathrm{C} 57 \mathrm{BL} / 6, P 2 \times 7 \mathrm{r}^{-1}$, Asc ${ }^{-/}$, and caspase-1 ${ }^{-/-}$macrophages stimulated with biglycan $(4 \mu \mathrm{g} / \mathrm{ml})$ for 4 hours. Data are given as mean $\pm \mathrm{SD} ; n=6 .{ }^{*} P<0.05$.

other experimental and human renal disorders $(57,58)$. In fact, enhanced renal and circulating levels of biglycan were associated with an induction of TNF- $\alpha$, IL-1 $\beta$, MCP- 1 , and RANTES in plasma samples from patients with AR and of RANTES in DN. Thus, biglycan triggers the expression of several chemokines in macrophages and dendritic cells via TLR2/4, thereby regulating the infiltration of $\mathrm{T}$ and $\mathrm{B}$ cells as well as macrophages in inflammatory renal disorders of various etiologies.

Our transient transfection model revealed the molecular mechanism of short-term-overexpressed soluble biglycan in the pathophysiology of LN. To further explore the long-term effects of biglycan on CXCL13 regulation, renal infiltration, and the subsequent outcome of organ function in LN, we generated a mouse model of MRL/lpr mice backcrossed to a biglycandeficient background. The lack of biglycan resulted in a marked reduction of CXCL13 in the kidney, plasma, and resident peritoneal macrophages. Consequently, lower numbers of B cells, mainly the B1 subpopulation, were detected in kidneys from MRL/lpr mice lacking biglycan. Furthermore, biglycan deficiency was associated with lower numbers of infiltrating macrophages and $\mathrm{T}$ cells and lower levels of the respective chemoattractants (MCP-1, RANTES, and MIP-1 $\alpha$ ) in kidneys from MRL/lpr mice. This caused a reduction in albuminuria and delayed kidney damage. These results clearly show that biglycan deficiency suppresses disease activity and prevents structural renal damage in lupus-prone MRL/lpr mice, whereas transient biglycan overexpression causes a severe form of $\mathrm{LN}$ in the MRL/lpr mouse model. This together with the fact that $B g n^{+/} \mathrm{MRL} / \mathrm{lpr}$ and $B g n^{-1-} \mathrm{MRL} / \mathrm{lpr}$ mice, backcrossed for 7 to 10 generations, represented incipient congenic strains, strongly indicates that 
A
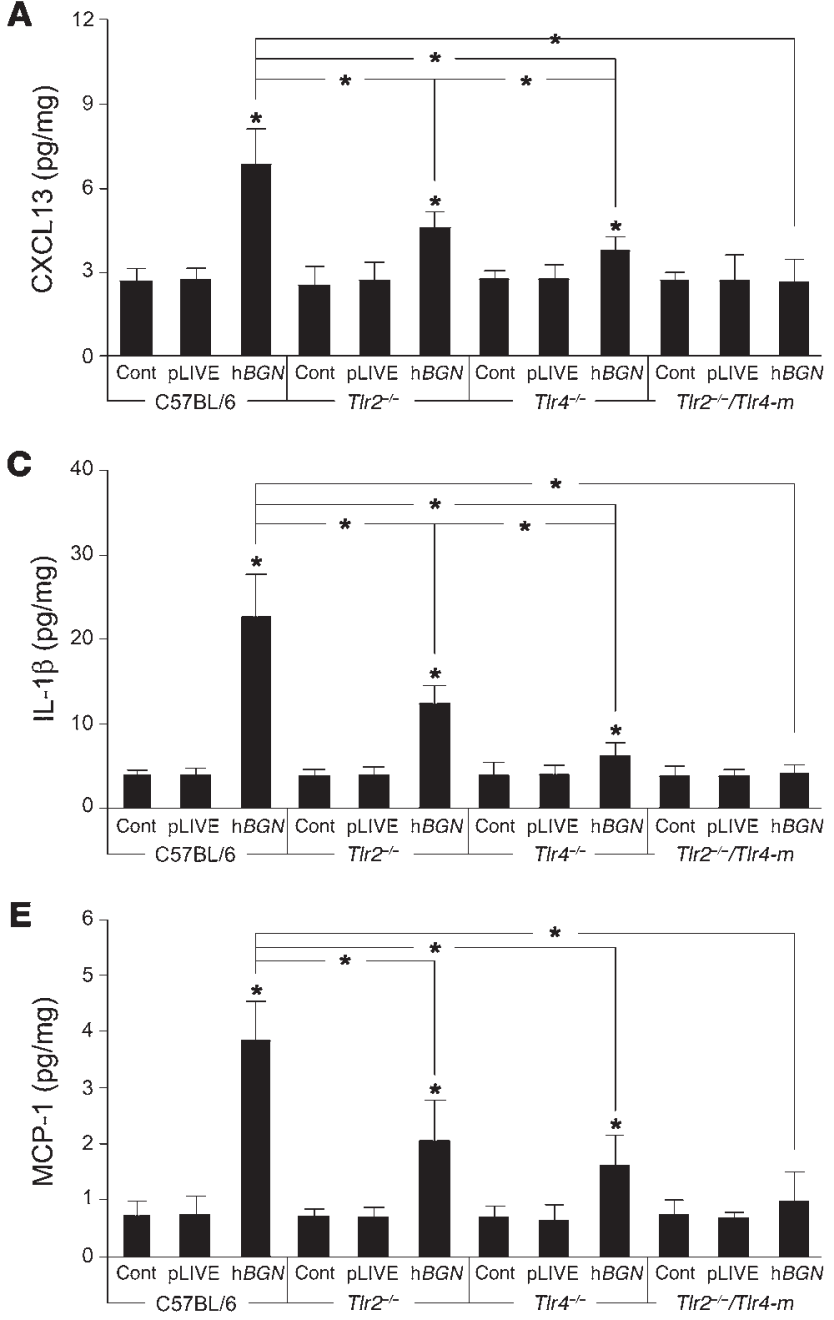
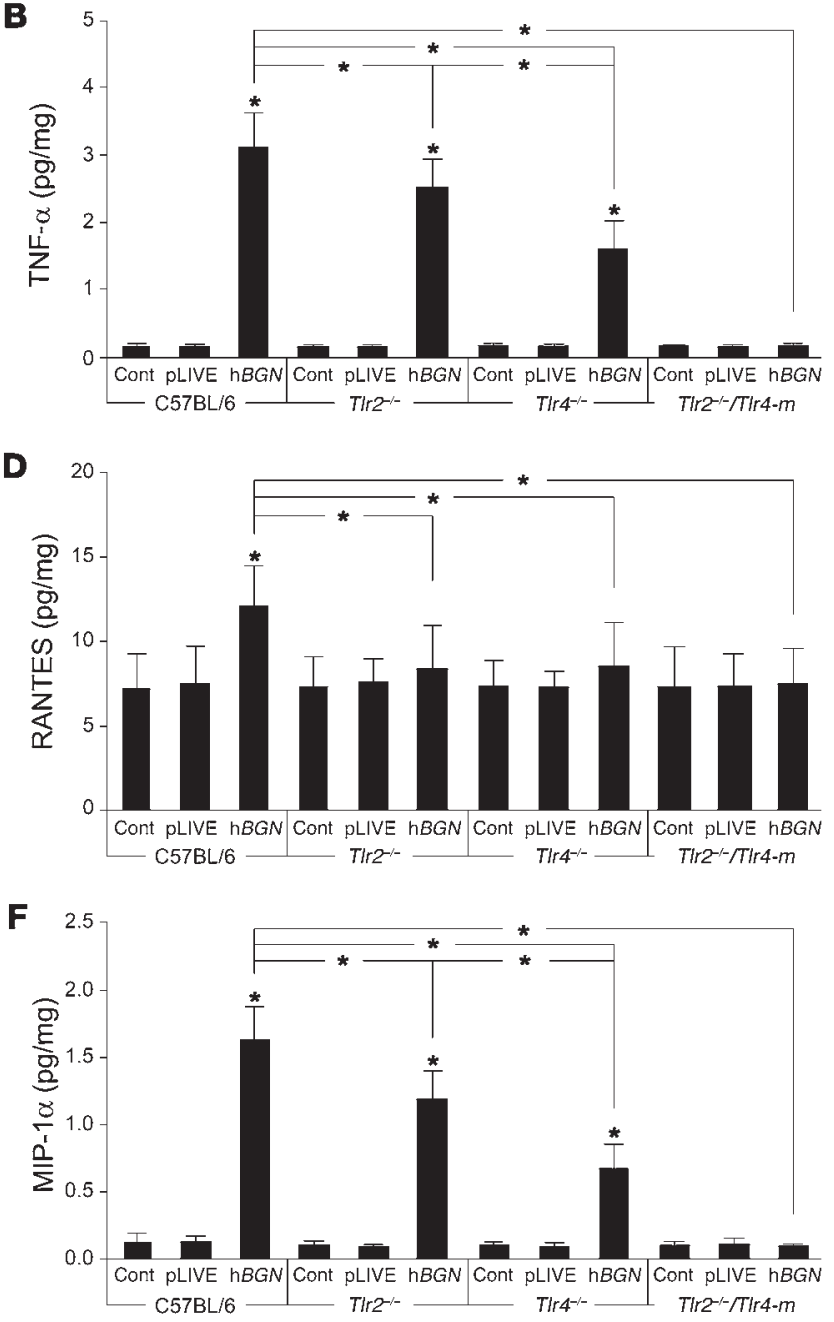

\section{Figure 10}

In vivo overexpression of soluble biglycan in healthy mice enhances renal and plasma levels of proinflammatory chemokines and cytokines via

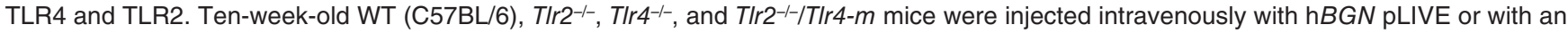
empty pLIVE vector or solvent to generate respective control mice, and 7 days following transfection were analyzed for CXCL13 (A), TNF- $\alpha$ (B), IL-1 $\beta$ (C), RANTES (D), MCP-1 (E), and MIP-1 $\alpha$ (F) protein in total kidney homogenates using ELISA. Chemokine and cytokine levels were normalized to total protein. Renal levels of all analyzed chemokines and cytokines, enhanced by the overexpression of soluble biglycan, were partially reduced in hBGN TIr2---, markedly decreased in hBGN TIr4---, and completely abrogated in kidneys from hBGN TIr2--/TIr4-m mice. Data are given as mean $\pm \mathrm{SD}$, and asterisks indicate statistical significance; $n=6$. ${ }^{*} P<0.05$.

the effects described above were in fact due to the deficiency in biglycan MRL/lpr mice lacking biglycan provided additional information on long-term effects of biglycan deficiency regarding the outcome of SLE. Besides delaying the progression of chronic renal failure, the lack of biglycan was associated with lower levels of circulating autoantibodies and reduced enlargement of the spleen and lymph nodes, demonstrating the strong influence of biglycan on the course and outcome of SLE.

In this study, we identified what we believe is a novel mechanism of CXCL13 regulation in the pathologies of the kidney. CXCL13 expression in macrophages and dendritic cells is driven by soluble biglycan, which in turn signals as a host-derived ligand through TLR2/4 with downstream involvement of ROS. In vivo, transient overexpression of biglycan in experimental SLE (MRL/lpr mouse model) with elevated circulating levels of the soluble proteoglycan was associated with high levels of CXCL13 in the plasma and kidney and worsened renal and systemic outcome, whereas biglycan deficiency resulted in a marked decline in CXCL13 with much reduced disease activity and less structural damage to the kidney. Importantly, we present evidence that biglycan triggers the expression of CXCL13 mRNA and protein in the kidney in a TLR2/4-dependent manner. Furthermore, we also provide in vivo evidence that biglycan was involved in the regulation of the inflammasome and of various macrophage and $\mathrm{T}$ cell chemoattractants in LN. A working model summarizing our results is shown in Figure 12. It is tempting to speculate that by bridging the innate and adaptive immune response, soluble endogenous biglycan might influence inflammation and thereby the course of SLE and various other B cell-mediated inflammatory disease entities as well. 


\section{Table 7}

Quantification of infiltrating mononuclear cells in kidneys from C57BL/6, TIr2--- TIr4 ${ }^{--}$, and TIr2--/TIr4-m mice overexpressing biglycan (immunohistochemical analysis)

\begin{tabular}{|c|c|c|c|}
\hline \multicolumn{2}{|c|}{ Genotype } & \multicolumn{2}{|c|}{ Mononuclear cells } \\
\hline & & $\begin{array}{l}\text { Total cell } \\
\text { number/hpf }\end{array}$ & $\begin{array}{l}\text { Perivascular } \\
\text { score }\end{array}$ \\
\hline C57BL/6 & $\begin{array}{l}\text { Cont } \\
\text { pLIVE } \\
\mathrm{h} B G N\end{array}$ & $\begin{array}{l}4.2 \pm 1.3 \\
4.5 \pm 1.0 \\
8.1 \pm 1.4^{\mathrm{A}}\end{array}$ & $\begin{array}{c}0 \pm 0 \\
0 \pm 0 \\
0.12 \pm 0.04^{A}\end{array}$ \\
\hline TIr2-- & $\begin{array}{l}\text { Cont } \\
\text { pLIVE } \\
\mathrm{h} B G N\end{array}$ & $\begin{array}{l}4.0 \pm 0.74 \\
4.2 \pm 1.1 \\
7.2 \pm 0.38^{A}\end{array}$ & $\begin{aligned} 0 & \pm 0 \\
0 & \pm 0 \\
0.08 & \pm 0.02^{\mathrm{A}, \mathrm{B}}\end{aligned}$ \\
\hline TIr $4^{-/-}$ & $\begin{array}{l}\text { Cont } \\
\text { pLIVE } \\
\mathrm{h} B G N\end{array}$ & $\begin{array}{l}4.4 \pm 0.47 \\
4.0 \pm 1.3 \\
6.3 \pm 0.62^{A, B}\end{array}$ & $\begin{aligned} 0 & \pm 0 \\
0 & \pm 0 \\
0.06 & \pm 0.02^{A, B}\end{aligned}$ \\
\hline TIr2--TIr4-m & $\begin{array}{l}\text { Cont } \\
\text { pLIVE } \\
\text { hBGN }\end{array}$ & $\begin{array}{l}4.1 \pm 0.66 \\
4.2 \pm 0.77 \\
4.8 \pm 0.67^{\mathrm{B}}\end{array}$ & $\begin{array}{l}0 \pm 0 \\
0 \pm 0 \\
0 \pm 0^{B}\end{array}$ \\
\hline $\begin{array}{l}\text { pLIVE, mice tr } \\
\text { hBGN, mice tr } \\
\text { inserted into th } \\
\text { Methods (hpf, } \\
\text { cell count. Val } \\
\text { AP }<0.05 \mathrm{hBG} \\
\text { BP }<0.05 \mathrm{hBG} \\
\mathrm{h} B G N \text { C57BL) }\end{array}$ & Ir2-1- hB & $\begin{array}{l}\text { or } 7 \text { days with th } \\
\text { or } 7 \text { days with hu } \\
\text { were quantified } \\
\text { gions were exclu } \\
\pm \text { SD for } n=6 \mathrm{p} \\
\text { ge-matched cor } \\
\text { or hBGN TIr2--- }\end{array}$ & $\begin{array}{l}\text { LIVE vector. } \\
\text { an biglycan } \\
\text { described in } \\
\text { d from the total } \\
\text { group. } \\
\text { (Cont) mice. } \\
4-m \text { versus }\end{array}$ \\
\hline
\end{tabular}

\section{Methods}

Patients and controls. Twelve patients of mixed European descent who had SLE, meeting at least 4 classification criteria of the American College of Rheumatology (59), including biopsy-proven diffuse proliferative LN (WHO class IV), were recruited at the Department of Nephrology and Rheumatology, University of Muenster, Germany. Patients exhibited clinical activity as defined by 1 or more of the following criteria: incident decline in renal function (serum creatinine $>1.0 \mathrm{mg} / \mathrm{dl}$ ), urinary protein excretion of $1 \mathrm{~g}$ or more per 24 hours, microscopic hematuria ( $>5$ red cells per high power-field), and the presence of cellular casts or serologic abnormalities (anti-DNS antibodies or hypocomplementemia). Patients with a GFR permanently less than $30 \mathrm{ml} / \mathrm{min}$ were excluded. Disease activity was calculated using the SLE Disease Activity Index (SLEDAI) (60). In addition, 5 healthy controls matched for sex and age were enrolled for CXCL13 measurements and biglycan content in their plasma. Normal renal tissue samples from patients who underwent tumor nephrectomy were used as controls for the histological analysis.

We also investigated patients suffering from $\mathrm{DN}(n=7)$ and patients with $\mathrm{AR}(n=6)$. The patients with $\mathrm{DN}$ were all type 2 diabetics with a known duration of diabetes of 13.5 years (8.9-18.3 years). The clinical characteristics of these patients and healthy controls $(n=8)$ are provided in the Supplemental Table 4. Serum levels of TNF- $\alpha$, IL-1 $\beta$, MCP-1, RANTES, and CXCL13 were measured by human-specific ELISA assays (R\&D Systems). Written informed consent was obtained from all participants. The study was performed in accordance with the declaration of Helsinki and approved by the institutional review board (Medical Faculty, University of Muenster).

Mice. MRL/MpJ-Fas ${ }^{l p r} / \mathrm{J}(\mathrm{MRL} / \mathrm{lpr}$ ) mice were purchased from The Jackson Laboratory. These mice carry a mutation in the apoptosis-related Fas gene, leading to autoreactive lymphocyte proliferation, closely mimick- ing human lupus erythematosus with lymphadenopathy, splenomegaly, hypergammaglobulinemia, and glomerulonephritis. The MRL mice (Jackson Laboratory), in spite of carrying the normal Fas gene, also develop lupus-like disease. However, the manifestation of disease is much slower, and therefore MRL is commonly used as a control strain for MRL/lpr mice. To supplement our findings, we ran additional experiments in 16-week-old female New Zealand black/New Zealand white NZB/W-F1 hybrid mice (The Jackson Laboratory), another model of lupus erythematosus (22). The Tlr2 $2^{-/-}$and Tlr4 $4^{-/}$, Tlr2 $2^{-/-} / \operatorname{Tl} 4-m$ (Tlr4- $m$ mice with a TLR4 gene point mutation, $\mathrm{C} 3 \mathrm{H} / \mathrm{HeJ}), \mathrm{Asc}^{-/-}$, and $\mathrm{P} 2 x 7 r^{-/}$mice were provided by M. Freudenberg (Max Planck Institute for Immunology, Freiburg, Germany), M. Kirschfink (Technical University of Munich, Germany), V. M. Dixit (Genentech, San Francisco, USA), and B. Sperlágh (Hungarian Academy of Sciences, Budapest, Hungary), respectively. C57BL/6 and $\mathrm{C} 3 \mathrm{H} / \mathrm{HeN}$ (WT strains for Tlr4-m) were purchased from Charles River Laboratories and Casp-1 $1^{\text {tm } 1 \text { Sesh }} /$ LtJ from The Jackson Laboratories. Biglycandeficient $\left(\mathrm{Bgn}^{-/-}\right)$mice were described previously (61).

Biglycan-deficient mice and MRL-Fas ${ }^{l p r}$ mice were bred to generate heterozygous F1 offspring. These animals were intercrossed to generate mice homozygous for both genotypes: $B g n^{-/-} \mathrm{MRL}$ and $B g n^{-1-\mathrm{MRL}} / \mathrm{lpr}$. These mice were backcrossed to MRL/lpr mice 7 to 10 times to generate biglycandeficient lupus-prone mice and their respective controls, $B g n^{+/} \mathrm{MRL}$ and $B g n^{+/+} \mathrm{MRL} / \mathrm{lpr}$. Genotyping was done by PCR using genomic DNA isolated from tail snips according to the manufacturer's directions (Roche Diagnostics $\mathrm{GmbH}$ ). Mice were housed and bred in a pathogen-free animal facility.

To generate mice overexpressing soluble biglycan, human biglycan cDNA $(\mathrm{h} B G N)$ was inserted into the Bam HI/SacII site of the pLIVE vector containing the mouse albumin promoter (Mirus). hBGN was overexpressed in 9-week-old female $B g n^{+/+} \mathrm{MRL} / \mathrm{lpr}$ and $\mathrm{Bg} n^{+/+} \mathrm{MRL}$ mice and in $\mathrm{C} 57 \mathrm{BL} / 6$, $\mathrm{Tlr} 2^{--}, \mathrm{Tlr} 4^{-/}$, and $\mathrm{Tlr} 2^{-/-} / \mathrm{Tl} 4-\mathrm{m}$ by a single intravenous injection of the $\mathrm{h} B G N$ pLIVE vector $(40 \mu \mathrm{g})$ in $300 \mu \mathrm{l} 5 \%$ glucose and $7.2 \mu \mathrm{l}$ ExGen In Vivo solution (Fermentas Life Sciences). For controls, vehicle or empty pLIVE vector was used. Mice were sacrificed at day 7 following injection. To analyze the expression of $\mathrm{h} B G N$, total RNA was extracted from liver, lungs, heart, skeletal muscle, and kidneys, followed by RT-PCR (62) using the primer pair 5'-TGGAGAACAGTGGCTTTGAA-3' and 5'-ACTACAACGGCATCAGCCTC-3', which encompasses bp 573-1001 of the human biglycan sequence (GenBank BC002416) with a 90\% cDNA sequence homology as compared with murine biglycan (bp 585-1013) (GenBank AK135496).

Due to a single SacI restriction site present in the human biglycan gene sequence, digestion of amplified cDNA with SacI resulted in 2 fragments (272 bp and $165 \mathrm{bp}$ ) of human compared with a single fragment (428 bp) of murine origin. Additionally, the primer pair 5'-AACAACCCTGTGCCCTACTG-3' and 5'-GCTTAGGAGTCAGGGGGAAG-3', which encompasses bp 1158-1380 of murine biglycan (GenBank AK135496) and does not recognize human biglycan cDNA, was used to detect endogenous biglycan expression in the mouse liver. Mouse Hprt1 encompassing bp 13-503 with the primer pair 5'-AGTCCCAGCGTCGTGATTAG-3' and 5'-AGAGGTCCTTTTCACCAGCA-3' was used as a housekeeping gene. Mice were divided into 3 experimental groups (injected with solvent, pLIVE, or hBGN pLIVE), each consisting of a minimum of 6 female animals. Spot urine samples were collected from mice, which were individually housed in metabolic cages immediately before euthanasia. Blood samples were obtained by cardiac puncture at the time of sacrifice. The weights of lymph nodes (mediastinal, axillary, inguinal, and mesenteric) and the spleen were measured to evaluate lymphadenopathy and splenomegaly. The following parameters were determined: albuminuria by the mouse Albuwell ELISA kit (Exocell Inc.), creatinine by the colorimetric Microplate Assay (Oxford Biomedical Research), circulating IgG (Bethyl Laboratories Inc.), and IgM (Assay designs) by ELISA techniques. 
A

$$
\begin{aligned}
& \frac{\text { Plasma }}{\text { Cont DN AR }} \frac{\text { St }}{0.3 \mu g} \\
& \text { Biglycan }
\end{aligned}
$$

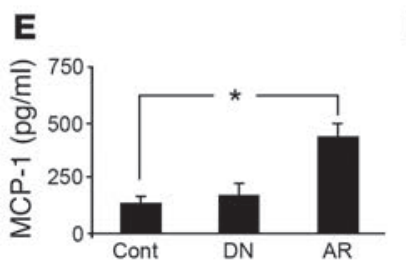

F
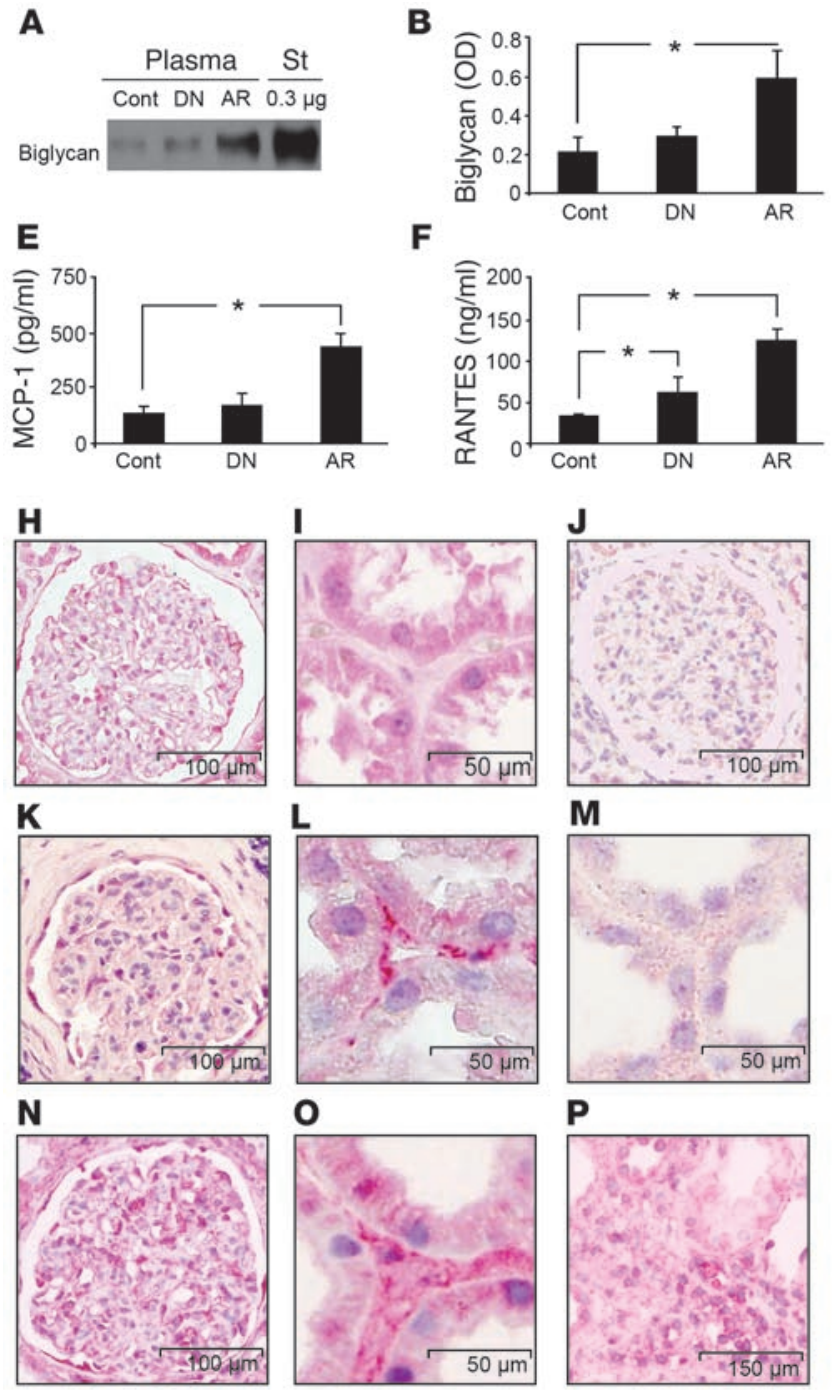

o

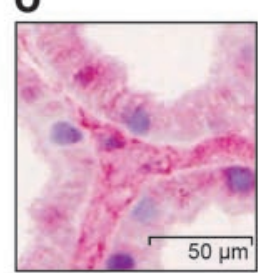

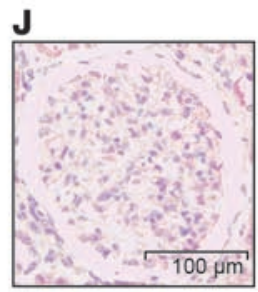

M

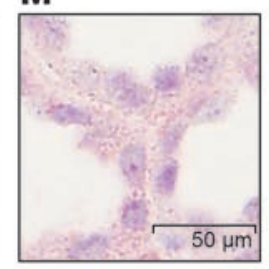

$\mathbf{P}$

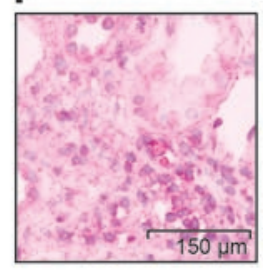

C

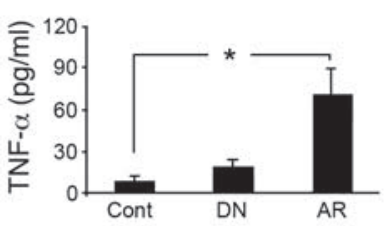

G

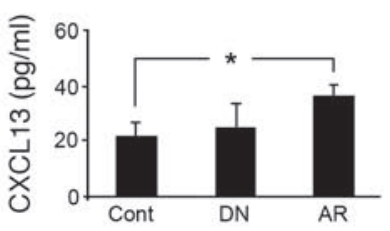

D

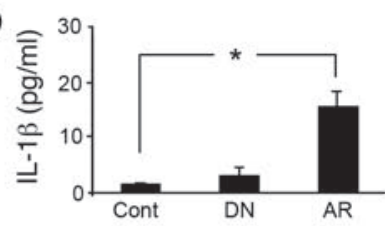

\section{Figure 11}

Correlation of biglycan levels in plasma and kidneys from patients with DN or AR with circulating proinflammatory cytokines (TNF- $\alpha$, IL-1 $\beta$ ) and chemokines (MCP-1, RANTES, and CXCL13). (A) Immunoblots for biglycan core protein after semipurification of $0.2 \mathrm{ml}$ plasma from healthy controls (Cont) and patients with DN or AR followed by chondroitinase $A B C$ digestion. All samples were purified simultaneously and under the same conditions. Standard contained $0.3 \mu \mathrm{g}$ of biglycan that was digested with chondroitinase ABC only. (B) Semiquantification of plasma biglycan calculated with consideration of the assay recovery. The net biglycan gain was calculated as indicated in the legend for Figure 1. (C-G) ELISA for (C) TNF- $\alpha$, (D) IL-1 $\beta$, (E) MCP-1, (F) RANTES, and (G) CXCL13 in plasma from healthy controls and patients with $\mathrm{DN}$ or $\mathrm{AR}$. Data are given as mean $\pm \mathrm{SD}$, and asterisks indicate statistical significance; $n=7$ for DN and $n=6$ for AR. ${ }^{*} P<0.05$. (H-P) Immunostaining for biglycan (APAAP, red color) in renal sections from patients with DN (K and $\mathbf{L})$ or AR ( $\mathbf{N}-\mathbf{P})$ or healthy controls $(\mathbf{H}$ and $\mathbf{I})$. Counterstaining was done with Meyer's hematoxylin. The negative control ( $\mathbf{J}$ and $\mathbf{M}$ ) was performed in renal sections from DN patients by using an antigen-preadsorbed (human biglycan) antiserum. Scale bars indicate the respective magnifications.

All animal work was conducted in accordance with the German Animal Protection Law and was approved by the Ethics Review Committee for laboratory animals of the district government of Darmstadt, Germany.

Detection of anti-dsDNA antibodies. For detection of anti-dsDNA antibodies, nitrocellulose-filtered, sonicated calf thymus DNA ( $1 \mu \mathrm{g} / \mathrm{ml}$ in PBS; SigmaAldrich) was pretreated with S1 nuclease (Fermentas Life Sciences) in order to eliminate single-stranded DNA molecules. Subsequently, double-stranded DNA was coated onto MaxiSorp Immunoplates (96-well; Nunc/Fisher Scientific $\mathrm{GmbH}$ ) for 12 hours at $4{ }^{\circ} \mathrm{C}$. Coated plates were blocked with $0.5 \%$ BSA (Sigma-Aldrich) at room temperature for 2 hours, and serum samples were loaded thereafter (diluted 1:100 and 1:500 in PBS). DNAbinding antibodies were detected with horseradish peroxidase-conjugated sheep anti-mouse polyimmunoglobin (GE Healthcare) for 2 hours at room temperature. The substrate orthophenylenediamine (R\&D Systems) was then added, and the absorbance of each well was read at $490 \mathrm{~nm}$. The levels of anti-dsDNA antibodies were reported as optical density.

Renal morphology and immunohistochemistry. Serial sections $(4 \mu \mathrm{m})$ of paraffin-embedded samples were either stained with PAS or H\&E or processed for immunohistochemical studies by immunoperoxidase or alkaline phosphatase anti-alkaline phosphatase techniques (APAAP) (62). The severity of renal lesions in murine $\mathrm{LN}$ was graded from 0 to 3

(for normal, mild, moderate, or severe) using the activity index described for human LN (24). For each mouse, at least 15 glomerular, tubular, or interstitial areas were graded and evaluated for glomerular cellularity, infiltrating leukocytes, mesangial matrix expansion, crescent formation, interstitial mononuclear cell infiltrates in the medulla and cortex, hyaline deposits, fibrinoid necrosis, and tubular atrophy, respectively. Lesion scores for each mouse were calculated as the mean of the summed individual scores for each image, with scores for necrosis and crescent formation weighted by a factor of 2 .

For immunohistochemistry, primary antibodies included the following: rat anti-mouse F4/80 (macrophage marker; $\mathrm{AbD}$ Serotec), rat anti-mouse CD3 (T cell marker; Santa Cruz Biotechnology Inc.), rabbit anti-murine biglycan antiserum (LF-106) provided by L.W. Fisher (63), and goat antihuman biglycan (R\&D Systems). Counterstaining was performed with Meyer's hematoxylin (Sigma-Aldrich). To prove that immunostainings by LF-106 antiserum and goat anti-human-biglycan were in fact specific for biglycan under control as well as LN, DN, and AR conditions, antibody binding to biglycan was neutralized by preabsorption with a 10 -fold excess of purified murine or human biglycan (3), respectively. Antisera were preincubated with purified biglycan for 12 hours at $4{ }^{\circ} \mathrm{C}$ prior to the incubation with tissue sections. Mouse biglycan from supernatants of mouse 


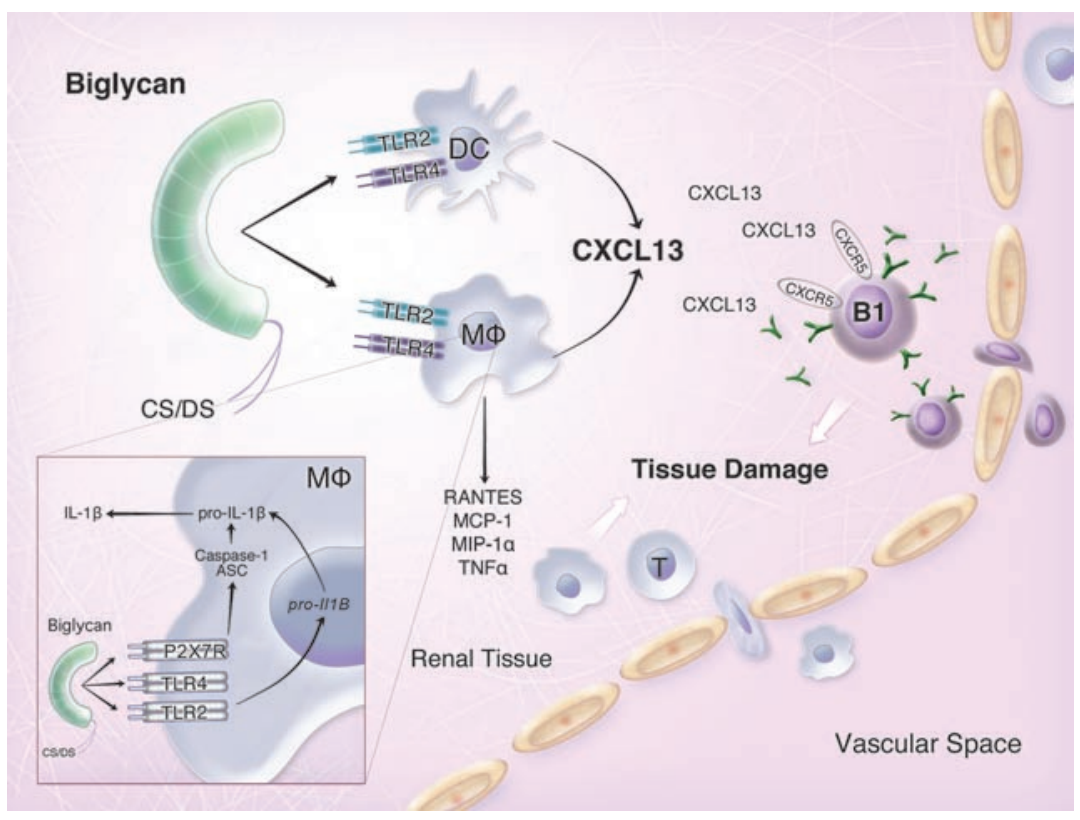

Figure 12

A working model summarizing the concept of biglycan-driven, CXCL13-mediated, and B cell-based inflammation in LN. Soluble biglycan acts as an endogenous danger signal in the kidney and triggers the expression of the B cell chemoattractant CXCL13 by signaling through TLR2 and TLR4 in interstitial macrophages and dendritic cells. Elevated levels of CXCL13 will result in recruitment of CXCR5-positive B cells, preferentially the B1 subset (B1) into the kidney. To further boost the inflammatory response, biglycan induces the synthesis of RANTES, MCP-1, and MIP- $1 \alpha$ in macrophages, thereby attracting T cells (T) and additional macrophages along an increasing gradient of chemoattractants. In consequence, lymph follicle-like clusters of B cells, T cells, and macrophages develop in the kidney. Furthermore, biglycan triggers the expression of pro-II1B mRNA via TLR2/4 in macrophages. By clustering TLR2/4 with P2X7R, biglycan stimulates inflammasomedependent IL-1 $\beta$ maturation via ASC and caspase-1 (left lower panel). However, P2X7R and the inflammasome are not contributing to the regulation of CXCL13 expression. Excessive activation and recruitment of lymphocytes followed by further cytokine/chemokine secretion and antibody production by $B$ lymphocytes will cause progressive inflammatory damage to the kidney. CS/DS, chondroitin/dermatan sulfate side chains.

skin fibroblasts was purified as described previously for human biglycan (3). Additional specificity controls included omission or replacement of primary antiserum with normal rat IgG or goat serum.

Infiltrating mononuclear cells were counted in 10 randomly selected nonoverlapping high-power fields (hpf) (hpf, $\times 400$ ) of renal sections. The number of macrophages and T cells was estimated per field (hpf, $\times 400$, with a minimum of 10 fields counted) (Soft Imaging System; Olympus). The amount of cells in perivascular regions was scored in 10 areas as follows: none $=0$, more than 5 cell layers surrounding the vessel $=1,5-10$ layers $=2$, and more than 10 layers $=3$. Sections were examined by a blinded observer.

Isolation and semiquantification of biglycan from tissue and plasma. Biglycan in homogenates from whole kidneys and plasma samples ( $n=6$ in each group) was extracted and semipurified as described previously $(2,62)$. The proteoglycan was then digested with chondroitinase ABC (Seikagaku Corp.) to remove glycosaminoglycan chains and subjected to polyacrylamide gel electrophoresis followed by Western blotting with subsequent quantification as described previously (62). The following primary antibodies were used: goat anti-human biglycan antibody (Acris Antibodies) and rabbit anti-mouse biglycan LF106 antibody (63). Signal detection was performed using the ECL Western blotting detection system (Pierce/Perbio Science) and optical den- sity of bands was obtained using Scion Image software (Scion Corp.). For validation of the assay, graded known amounts of intact biglycan (containing the protein core and glycosaminoglycan chains) (3) were added to human plasma from healthy controls, patients with LN, plasma,

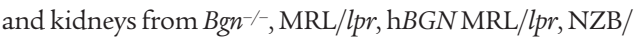
W-F1 mice, and their respective controls. All samples were purified and digested with chondroitinase $\mathrm{ABC}$ in parallel and under the same conditions.

The net biglycan gain was calculated by subtracting the band intensity of endogenous biglycan protein core from that of the extracted biglycan protein core from the same sample and in the presence of a known quantity of exogenous biglycan. The gain was then expressed as percentage of density as denominated by the standard. The standard contained the same amount of biglycan as added to the sample, was digested with chondroitinase $\mathrm{ABC}$, and loaded onto the gel. The recovery after all purification steps was linear in the range of $0.1-0.4 \mu \mathrm{g}$ and varied between the experimental groups to the same extent (human plasma: controls: $86 \% \pm 3 \%$ vs. $\mathrm{LN}$ : $84 \% \pm 3 \%$; mouse plasma: MRL: $87 \% \pm 5 \%$ vs. MRL/lpr: $83 \% \pm 6 \%$; mouse kidney: MRL: $86 \% \pm 7 \%$ vs. MRL/lpr: $83 \% \pm 2 \% ; n=3$ in each group) in accordance with data previously observed under similar assay conditions (62, 64). Renal biglycan content was calculated per whole kidney or per mg protein of the kidney homogenate used for the proteoglycan isolation. The results of 3 samples per group were averaged.

Isolation of renal mononuclear and spleen dendritic cells. Mouse kidneys were removed, washed in ice-cold PBS (Invitrogen $\mathrm{GmbH}$ ), and minced into 2- to 5-mm fragments followed by incubation with $0.5 \mathrm{mg} / \mathrm{ml}$ collagenase A (Roche Diagnostics GmbH) in PBS for 15 minutes at $37^{\circ} \mathrm{C}$. Subsequently, tissue was sieved using 70 - and 30-micron cell strainers (BD). Six kidneys from each genotype were pooled for 1 analysis. Renal cell suspensions were depleted of erythrocytes by using ice-cold $0.15 \mathrm{M}$ ammonium chloride, $0.1 \mathrm{mM}$ sodium EDTA, $1.0 \mathrm{mM}$ potassium carbonate, $\mathrm{pH} 7.2$ (ACK buffer). Subsequently, mononuclear cells were purified by the Histopaque (Sigma-Aldrich) density gradient method according to the manufacturer's instruction. Mononuclear cells were counted, and $10^{6}$ cells were used for FACS analysis. For analyzing renal B1 cells, mononuclear cells were isolated from the kidneys as described above and after purification by Histopaque density gradient, the CD19+ $\mathrm{B}$ cells were selected from the mononuclear cell suspension using CD19-MicroBeads and MACS Technology (MACS Miltenyi Biotech). $10^{6} \mathrm{CD} 19^{+}$cells were used for FACS analysis. Five independent experiments were performed.

Dendritic cells were isolated from murine spleen by mincing tissue with scalpels in ice-cold PBS followed by progressive sieving, using 70- and 30micron cell strainers (BD), treated with ACK buffer, and centrifuged in a density gradient as described for kidneys. Separation of dendritic cells from the mononuclear cell suspension was performed using CD11c MicroBeads and MACS Technology.

FACS. Renal mononuclear cells were counted and stained with PElabeled anti-CD5, PerCP-labeled anti-CD3, or FITC-labeled anti-CD19 monoclonal antibodies, or the respective isotype controls. Unspecific staining was blocked by preincubation of cells with anti-mouse CD16/32 Fc block for 10 minutes. The cells were washed with PBS containing $2 \%$ FBS and $0.1 \% \mathrm{NaN}_{3}$, and then fixed with $1 \%$ paraformaldehyde. Dead cells were 
excluded from analysis by adding 7-amino-actinomycin D (7-AAD) before measurement. All reagents were purchased from eBioScience (eBioScience/ NatuTec). Flow cytometry was carried out with the FACSCanto II Flow Cytometer (BD) and FACSDiva Software (BD).

Stimulation of peritoneal macrophages and spleen dendritic cells. Resident peritoneal macrophages were harvested by lavage and cultured in RPMI 1640 (Invitrogen) under serum-free conditions. Only adherent cells were used for primary cultures. The purity of cells was controlled by FACS and Giemsa staining. To elucidate the effect of biglycan on CXCL13 expression, resident peritoneal macrophages were collected from 16-week-old $\mathrm{Bgn}^{+/+}$and $B g n^{-1-\mathrm{MRL}}$ and MRL/lpr mice, and Cxcl13 mRNA (qRT-PCR) and protein levels (ELISA) were measured after 12 hours of culture under serum-free conditions without stimulation.

Additionally, residential peritoneal macrophages or mature spleen den-

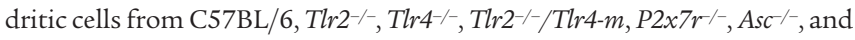
caspase $-1^{-/-}$mice were stimulated with intact human biglycan $(4 \mu \mathrm{g} / \mathrm{ml}$ for 4 hours) and quantitatively assessed for Cxcl13 by qRT-PCR and/or ELISA. When required, macrophages were preincubated for 1 hour at $37^{\circ} \mathrm{C}$ with $\mathrm{N}$-acetyl-L-cysteine (NAC) (10 mM solution in RPMI 1640 adjusted to a $\mathrm{pH}$ of 7.4) (Enzo Life Sciences) or DPI (0.5 $\mu \mathrm{M}$; Sigma-Aldrich). The expression of human biglycan in $293 \mathrm{HEK}$ cells and purification of the native proteoglycan, containing 2 chondroitin/dermatan sulfate chains, has previously been described (3). Alternatively to the stimulation with biglycan, macrophages and dendritic cells were also incubated with ultra-pure LPS from Salmonella minnesota ( $2 \mathrm{ng} / \mathrm{ml}$; InvivoGen) and peptidoglycan from Staphylococcus aureus ( $5 \mu \mathrm{g} / \mu \mathrm{l}$; Sigma-Aldrich) for 4 hours, followed by TNF- $\alpha$ determination (ELISA) in the supernatants.

qRT-PCR. Total RNA was extracted from kidney, liver, and lung samples and from macrophages and dendritic cells using TRIzOL reagent (Invitrogen) as described (62). Quantitative TaqMan PCRs for Cxcl13, Cxcr5, biglycan, pro-Il1B, Nlrp3, and Gapdh were performed (Applied Biosystems). Amplification was detected by an increased fluorescent signal of 5-([N-[30-diphenylphosphinyl-40-methoxycarbonyl] phenyl carbonyl] aminoacetamido) fluorescein (FAM), using the ABI PRISM 7500 sequence detection system (Applied Biosystems). Assay probes for Cxcl13 (Mm 00444534_m1), Cxcr5 (Mm_99999118_m1), biglycan (Mm_01191751_g1), pro-Il1B (Mm_00434228_m1), Nlrp3 (Mm_00840904_m1), and Gapdh (Mm_03302249_g1), as well as the TaqMan Master Mix were purchased from Applied Biosystems.

ELISA and Western blotting. Plasma and tissue homogenates were used to determine CXCL13, TNF- $\alpha$, IL-1 $\beta$, RANTES, MCP- 1 , and MIP- $1 \alpha$ protein levels. Tissue was homogenized and sonicated in lysis buffer containing $137 \mathrm{mM} \mathrm{NaCl}, 20 \mathrm{mM}$ Tris/ $\mathrm{HCl}, \mathrm{pH}$ 8.0, 5 mM EDTA, 10\% glycerol, and $1 \%$ Triton X-100 and centrifuged at $4^{\circ} \mathrm{C}$ at $14,000 \mathrm{~g}$ for 15 minutes; supernatants were snap-frozen and stored at $-80^{\circ} \mathrm{C}$. Cytokine and chemokine levels in plasma and tissue samples were measured by mouse-specific ELISA assays (R\&D Systems) and in the case of tissue measurements, normalized to the protein content of the homogenates.

Anti-human biglycan antibody titers were determined in plasma by ELISA. Maxisorp Immunoplates (96-well; Nunc/Fisher Scientific GmbH) were coated with $1.5 \mu \mathrm{g} /$ well of chondroitinase ABC-digested (Seikagaku Corp.) human biglycan dissolved in carbonate buffer $\left(15 \mathrm{mM} \mathrm{Na}_{2} \mathrm{CO}_{3}\right.$, $35 \mathrm{mM} \mathrm{NaHCO}$, $\mathrm{pH}$ 9.6) for 12 hours at $4^{\circ} \mathrm{C}$. Free binding capacity of the wells was blocked by $0.1 \%$ BSA (Sigma-Aldrich) in PBS for 1 hour at $4^{\circ} \mathrm{C}$. Plasma dilutions of 1:500, 1:12,500, and 1:62,500 in PBS were used to detect biglycan-specific antibodies. Antibodies were detected with a sheep-anti-mouse HRP-conjugated antibodies (GE Healthcare) for 2 hours at room temperature, followed by the substrate orthophenylenediamine (R\&D Systems). For generation of a standard curve of mouse IgG isotypes, control protein (R\&D Systems) was titrated on the same plate. Absorbance was determined spectrophotometrically at $490 \mathrm{~nm}$. All assays were performed in duplicate, and each experiment was carried out at least 3 times.

Western and dot blots were performed and quantified as described (62). The following primary antibodies were used: goat anti-human biglycan antibody (Acris Antibodies), rabbit anti-mouse biglycan LF106 antibody (63), anti-mouse caspase- 1 and anti- $\beta$-tubulin (both from Santa Cruz Biotechnology Inc.).

Statistics. Data are given as mean \pm SD analyzed by 1 -way ANOVA, with Dunnett's significance correction test (SPSS Software). Differences were considered significant at $P<0.05$.

\section{Acknowledgments}

This work was supported by the Deutsche Forschungsgemeinschaft (SFB 815, project A5 to L. Schaefer and project A7 to J. Pfeilschifter, SCHA 1082/2-1 to L. Schaefer, GRK 1172 and Excellence Cluster ECCPS), Else Kröner-Fresenius-Stiftung, and by the Intramural Research Program of NIH/NIDCR (to M.F. Young). The excellent technical support of Riad Haceni is highly appreciated. We thank Chad Casey for his excellent work with the graphic design.

Received for publication January 4, 2010, and accepted in revised form September 22, 2010.

Address correspondence to: Liliana Schaefer, Pharmazentrum Frankfurt, Institut für Allgemeine Pharmakologie und Toxikologie, Klinikum der JW Goethe-Universität Frankfurt am Main, Haus 74, Z. 3.108a, Theodor-Stern-Kai 7, 60590 Frankfurt am Main, Germany. Phone: 49.69.6301.7899; Fax: 49.69.6301.83027; E-mail: Schaefer@med.uni-frankfurt.de.
1. Schaefer L, Iozzo RV. Biological functions of the small leucine-rich proteoglycans: from genetics to signal transduction. J Biol Chem. 2008; 283(31):21305-21309.

2. Schaefer L, et al. The matrix component biglycan is proinflammatory and signals through Toll-like receptors 4 and 2 in macrophages. J Clin Invest. 2005; 115(8):2223-2233.

3. Babelova A, et al. Biglycan, a danger signal that activates the NLRP3 inflammasome via toll-like and P2X receptors. J Biol Chem. 2009; 284(36):24035-24048.

4. Schaefer L, et al. Small proteoglycans of normal adult human kidney: distinct expression patterns of decorin, biglycan, fibromodulin, and lumican. Kidney Int. 2000;58(4):1557-1568.

5. Schaefer L, et al. Absence of decorin adversely influences tubulointerstitial fibrosis of the obstructed kidney by enhanced apoptosis and increased inflammatory reaction. Am J Pathol. 2002; 160(3):1181-1191.

6. Wu H, et al. TLR4 activation mediates kidney ischemia/reperfusion injury. J Clin Invest. 2007; 117(10):2847-2859.

7. Leemans JC, et al. The role of Toll-like receptor 2 in inflammation and fibrosis during progressive renal injury. PLoS One. 2009;4(5):e5704.

8. Helmick CG, et al. Estimates of the prevalence of arthritis and other rheumatic conditions in the United States. Part I. Arthritis Rheum. 2008;58(1):15-25.

9. Rahman A, Isenberg DA. Systemic lupus erythematosus. NEngl J Med. 2008;358(9):929-939.

10. Segerer S, Schlondorff D. B cells and tertiary lymphoid organs in renal inflammation. Kidney Int. 2008;73(5):533-537.

11. Kulkarni O, Anders HJ. Chemokines in lupus nephritis. Front Biosci. 2008;13:3312-3320.

12. Martin F, Oliver AM, Kearney JF. Marginal zone and B1 B cells unite in the early response against $\mathrm{T}$-independent blood-borne particulate antigens. Immunity. 2001;14(5):617-629.

13. Ha SA, et al. Regulation of B1 cell migration by signals through Toll-like receptors. J Exp Med. 2006;203(11):2541-2550.

14. Herzenberg LA. B-1 cells: the lineage question revisited. Immunol Rev. 2000;175:9-22.

15. Herzenberg LA, Stall AM, Lalor PA, Sidman C, Moore WA, Parks DR. The Ly-1 B cell lineage. Immunol Rev. 1986;93:81-102.

16. Schiffer L, et al. B-cell-attracting chemokine CXCL13 as a marker of disease activity and renal involvement in systemic lupus erythematosus (SLE). Nephrol Dial Transplant. 2009;24(12):3708-3712.

17. Tucci M, Ciavarella S, Strippoli S, Dammacco F, 
Silvestris F. Oversecretion of cytokines and chemokines in lupus nephritis is regulated by intraparenchymal dendritic cells: a review. Ann N Y Acad Sci. 2009;1173:449-457.

18. Allam R, Anders HJ. The role of innate immunity in autoimmune tissue injury. Curr Opin Rheumatol. 2008;20(5):538-544

19. Robson MG. Toll-like receptors and renal disease. Nephron Exp Nephrol. 2009;113(1):e1-7.

20. Marshak-Rothstein A, Rifkin IR. Immunologically active autoantigens: the role of toll-like receptors in the development of chronic inflammatory disease. Annu Rev Immunol. 2007;25:419-441.

21. Perez de Lema G, et al. Chemokine expression precedes inflammatory cell infiltration and chemokine receptor and cytokine expression during the initiation of murine lupus nephritis. J Am Soc Nephrol. 2001;12(7):1369-1382.

22. Dubois EL, Horowitz RE, Demopoulos HB, Teplitz R. NZB/NZW mice as a model of systemic lupus erythematosus. JAMA. 1966;195(4):285-289.

23. Shlomchik MJ, Aucoin AH, Pisetsky DS, Weigert MG. Structure and function of anti-DNA autoantibodies derived from a single autoimmune mouse. Proc Natl Acad Sci U S A. 1987;84(24):9150-9154.

24. Austin HA 3rd, Muenz LR, Joyce KM, Antonovych TT, Balow JE. Diffuse proliferative lupus nephritis: identification of specific pathologic features affecting renal outcome. Kidney Int. 1984;25(4):689-695.

25. Ishikawa $S$, et al. Aberrant high expression of B lymphocyte chemokine (BLC/CXCL13) by $\mathrm{C} 11 \mathrm{~b}+\mathrm{CD} 11 \mathrm{c}+$ dendritic cells in murine lupus and preferential chemotaxis of B1 cells towards BLC. J Exp Med. 2001;193(12):1393-1402.

26. Gunn MD, Ngo VN, Ansel KM, Ekland EH, Cyster JG, Williams LT. A B-cell-homing chemokine made in lymphoid follicles activates Burkitt's lymphoma receptor-1. Nature. 1998;391(6669):799-803.

27. Forster R, Mattis AE, Kremmer E, Wolf E, Brem G, Lipp M. A putative chemokine receptor, BLR1, directs $B$ cell migration to defined lymphoid organs and specific anatomic compartments of the spleen. Cell. 1996;87(6):1037-1047.

28. Ito $\mathrm{T}$, et al. Defective B1 cell homing to the peritoneal cavity and preferential recruitment of B1 cells in the target organs in a murine model for systemic lupus erythematosus. J Immunol. 2004;172(6):3628-3634.

29. Hojgaard A, Close R, Dunn DM, Weiss RB, Weis JJ, Weis JH. Altered localization of CXCL13 expressing cells in mice deficient in Pactolus following an inflammatory stimulus. Immunology. 2006; 119(2):212-223.

30. Schiffer L, et al. Activated renal macrophages are markers of disease onset and disease remission in lupus nephritis. J Immunol. 2008;180(3):1938-1947.

31. Kerjaschki D, et al. Lymphatic neoangiogenesis in human kidney transplants is associated with immunologically active lymphocytic infiltrates. J Am Soc Nephrol. 2004;15(3):603-612.

32. Steinmetz OM, et al. BCA-1/CXCL13 expression is associated with CXCR5-positive B-cell cluster formation in acute renal transplant rejection. Kidney Int. 2005;67(4):1616-1621.
33. Steinmetz OM, Stahl RA, Panzer U. Formation of lymphoid-like tissue in the kidney--is there a role for chemokines? Nephrol Dial Transplant. 2007; 22(2):350-352.

34. Yamamoto K, Loskutoff DJ. Expression of transforming growth factor-beta and tumor necrosis factor-alpha in the plasma and tissues of mice with lupus nephritis. Lab Invest. 2000;80(10):1561-1570.

35. Ferraccioli G, Romano G. Renal interstitial cells, proteinuria and progression of lupus nephritis: new frontiers for old factors. Lupus. 2008;17(6):533-540.

36. Border WA, Okuda S, Languino LR, Ruoslahti E. Transforming growth factor-beta regulates production of proteoglycans by mesangial cells. Kidney Int 1990;37(2):689-695.

37. Mozes MM, Bottinger EP, Jacot TA, Kopp JB. Renal expression of fibrotic matrix proteins and of transforming growth factor-beta (TGF-beta) isoforms in TGF-beta transgenic mice. J Am Soc Nephrol. 1999;10(2):271-280.

38. Ungefroren H, Krull NB. Transcriptional regulation of the human biglycan gene. J Biol Chem. 1996;271(26):15787-15795.

39. Schaefer L. Extracellular matrix molecules: endogenous danger signals as new drug targets in kidney diseases. Curr Opin Pharmacol. 2010;10(2):185-190.

40. Monfort J, et al. Degradation of small leucine-rich repeat proteoglycans by matrix metalloprotease13: identification of a new biglycan cleavage site. Arthritis Res Ther. 2006;8(1):R26.

41. Schaefer L, Schaefer RM. Proteoglycans: from structural compounds to signaling molecules. Cell Tissue Res. 2010;339(1):237-246.

42. Merline R, Schaefer RM, Schaefer L. The matricellular functions of small leucine-rich proteoglycans (SLRPs). J Cell Commun Signal. 2009;3(3-4):323-335.

43. Lim AK, Ma FY, Nikolic-Paterson DJ, Kitching AR, Thomas MC, Tesch GH. Lymphocytes promote albuminuria, but not renal dysfunction or histological damage in a mouse model of diabetic renal injury. Diabetologia. 2010;53(8):1772-1782.

44. Wahab NA, et al. Glomerular expression of thrombospondin-1, transforming growth factor beta and connective tissue growth factor at different stages of diabetic nephropathy and their interdependent roles in mesangial response to diabetic stimuli. Dia betologia. 2005;48(12):2650-2660.

45. Ziyadeh FN. Mediators of diabetic renal disease: the case for tgf-Beta as the major mediator. $J \mathrm{Am}$ Soc Nephrol. 2004;15 suppl 1:S55-S57.

46. Heller F, et al. The contribution of B cells to renal interstitial inflammation. Am J Pathol. 2007; 170(2):457-468.

47. Steinmetz OM, et al. Analysis and classification of B-cell infiltrates in lupus and ANCA-associated nephritis. Kidney Int. 2008;74(4):448-457.

48. Suto H, Katakai T, Sugai M, Kinashi T, Shimizu A. CXCL13 production by an established lymph node stromal cell line via lymphotoxin-beta receptor engagement involves the cooperation of multiple signaling pathways. Int Immunol. 2009;21(4):467-476.

49. Perrier P, et al. Distinct transcriptional programs activated by interleukin-10 with or without lipo- polysaccharide in dendritic cells: induction of the B cell-activating chemokine, CXC chemokine ligand 13. J Immunol. 2004;172(11):7031-7042.

50. Rupprecht TA, et al. Borrelia garinii induces CXCL13 production in human monocytes through Toll-like receptor 2. Infect Immun. 2007;75(9):4351-4356.

51. van de Pavert SA, et al. Chemokine CXCL13 is essential for lymph node initiation and is induced by retinoic acid and neuronal stimulation. Nat Immunol. 2009;10(11):1193-1199.

52. Qin J, et al. Developmental stage-dependent collaboration between the TNF receptor-associated factor 6 and lymphotoxin pathways for B cell follicle organization in secondary lymphoid organs. JImmunol. 2007;179(10):6799-6807.

53. Liu B, et al. TLR4 up-regulation at protein or gene level is pathogenic for lupus-like autoimmune disease. J Immunol. 2006;177(10):6880-6888.

54. Komatsuda A, et al. Up-regulated expression of Toll-like receptors mRNAs in peripheral blood mononuclear cells from patients with systemic lupus erythematosus. Clin Exp Immunol. 2008; 152(3):482-487.

55. Alugupalli KR, Leong JM, Woodland RT, Muramatsu M, Honjo T, Gerstein RM. B1b lymphocytes confer T cell-independent long-lasting immunity. Immunity. 2004;21(3):379-390

56. Haas KM, Poe JC, Steeber DA, Tedder TF. B-1a and $\mathrm{B}-1 \mathrm{~b}$ cells exhibit distinct developmental requirements and have unique functional roles in innate and adaptive immunity to $\mathrm{S}$. pneumoniae. Immunity. 2005;23(1):7-18

57. Anders HJ, Vielhauer V, Schlondorff D. Chemokines and chemokine receptors are involved in the resolution or progression of renal disease. Kidney Int. 2003;63(2):401-415

58. Panzer U, Steinmetz OM, Stahl RA, Wolf G. Kidney diseases and chemokines. Curr Drug Targets. 2006;7(1):65-80.

59. Hochberg MC. Updating the American College of Rheumatology revised criteria for the classification of systemic lupus erythematosus. Arthritis Rheum. 1997;40(9):1725.

60. Bombardier C, Gladman DD, Urowitz MB, Caron $\mathrm{D}$, Chang CH. Derivation of the SLEDAI. A disease activity index for lupus patients. The Committee on Prognosis Studies in SLE. Arthritis Rheum. 1992;35(6):630-640.

61. Xu T, et al. Targeted disruption of the biglycan gene leads to an osteoporosis-like phenotype in mice. Nat Genet. 1998;20(1):78-82.

62. Schaefer L, et al. Small proteoglycans in human diabetic nephropathy: discrepancy between glomerular expression and protein accumulation of decorin, biglycan, lumican, and fibromodulin. FASEB J. 2001;15(3):559-561.

63. Fisher LW, Stubbs JT 3rd, Young MF. Antisera and cDNA probes to human and certain animal model bone matrix noncollagenous proteins. Acta Orthop Scand Suppl. 1995;266:61-65.

64. Schaefer L, et al. Biglycan, a nitric oxide-regulated gene, affects adhesion, growth, and survival of mesangial cells. J Biol Chem. 2003;278(28):26227-26237. 